This dissertation has been microfilmed exactly as received

$67-3958$

EDWA RDS, Harry Wallace, 1939-

THE ADSORPTION OF METHANOL VAPOR ON SILVER IODIDE.

University of Arizona, Ph.D., 1966

Chemistry, physical

University Microfilms, Inc., Ann Arbor, Michigan 


\title{
THE ADSORPTION OF METHANOL VAPOR ON SILVER IODIDE
}

\author{
$\operatorname{by}_{1} \sim^{2 \prime}$ \\ Harry W. Edwards
}

A Dissertation Submitted to the Faculty of the DEPARTMENT OF CHEMISTRY

In Partial Fulfillment of the Requirements For the Degree of DOCTOR OF PHILOSOPHY

In the Graduate College THE UNIVERSITY OF ARIZONA 
THE UNIVERSITY OF ARIZONA

GRADUATE COLLEGE

I heręby recommend that this dissertation prepared under my direction by Harry W. Edwards entitled The Adsorption of Methanol Vapor on Silver Iodide

be accepted as fulfilling the dissertation requirement of the degree of Doctor of Philosophy

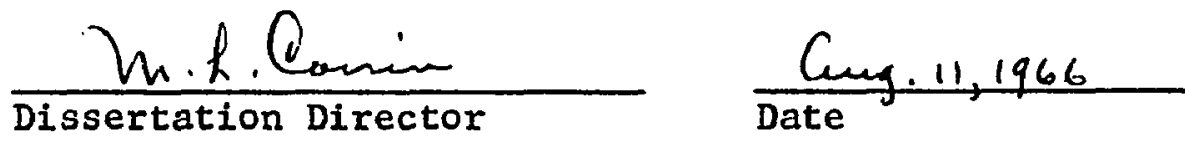

After inspection of the dissertation, the following members of the Final Examination Committee concur in its approval and recommend its acceptance:*
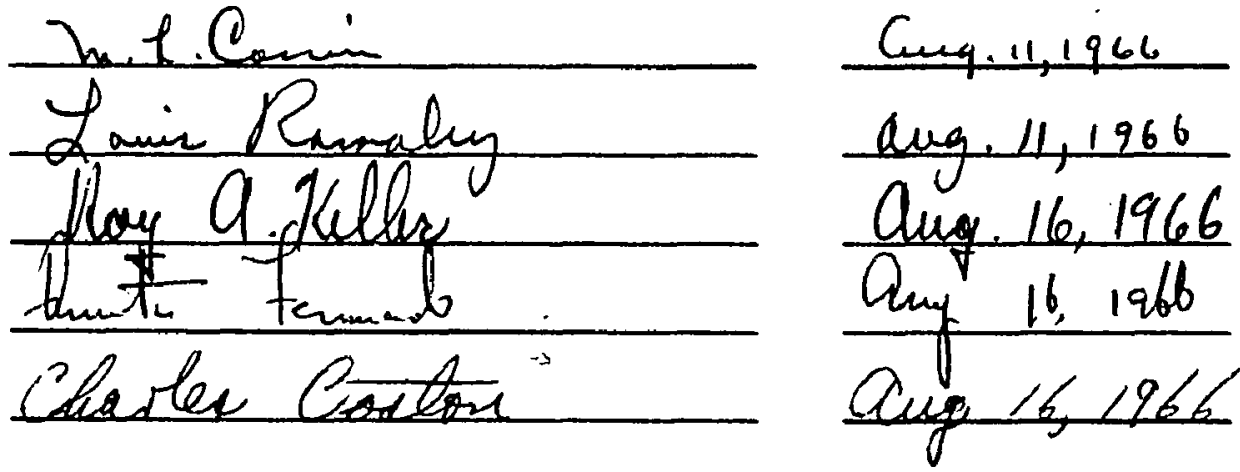

*This approval and acceptance is contingent on the candidate's adequate performance and defense of this dissertation at the final oral examination. The inclusion of this sheet bound into the library copy of the dissertation is evidence of satisfactory performance at the final examination. 


\section{STATEMENT BY AUTHOR}

This dissertation has been submitted in partial fulfillment of requirements for an advanced degree at The University of Arizona and is deposited in the University Library to be made available to borrowers under rules of the Library.

Brief quotations from this dissertation are allowable without special permission, provided that accurate acknowledgment of source is made. Requests for permission for extended quotation from or reproduction of this manuscript in whole or in part may be granted by the head of the major department or the Dean of the Graduate College when in his judgment the proposed use of the material is in the interests of scholarship. In all other instances, however, permission must be obtained from the author.

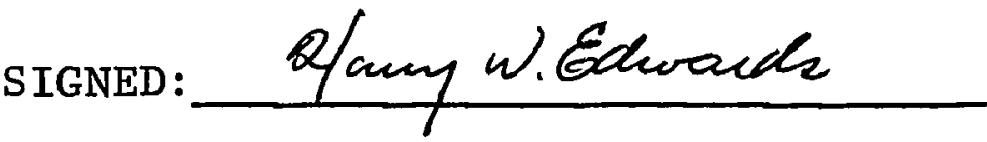




\section{ACKNOWLEDGMENTS}

The author wishes to express his sincere gratitude to Dr. M. L. Corrin for his guidance and patience throughout the course of this work.

The author is especially grateful to his wife, Ruth, who assisted in typing the manuscript.

The work reported in this dissertation was financially supported by the National Science Foundation. The award of a General Electric Foundation Fellowship in Chemistry for the academic year 1965-66 is gratefully acknowledged. 
TABLE OF CONTENTS

Page

LIST OF TABLES . . . . . . . . . . . . . . . . vi

LIST OF ILLUSTRATIONS . . . . . . . . . . . . . vii

ABSTRACT . . . . . . . . . . . . . . viii

INTRODUCTION . . . . . . . . . . . . . . . . 1

Formation of a Condensed Phase from a Vapor . . . 1

Adsorption of a Gas on a Solid ......... 9

Silver Iodide as a Nucleant for Water Vapor . . . 16

STATEMENT OF THE PROBLEM . . . . . . . . . . . 24

EXPERIMENTAL . . . . . . . . . . . . . 29

The Adsorption of Water Vapor on Silver Iodide. . 29

Materials . . . . . . . . . . 29

Apparatus ............... . 30

Adsorption Measurements . . . . . . . 32

Effect of Mercury Vapor on Methanoi Adsorption. 38

Apparatus . . . . . . . . . . 38

Procedure ................ 40

Adsorption of Methanol Vapor on Silver Iodide . . 42

Materials . . . . . . . . . . . . . 42

Temperature Measurement and Control . . . 45

The Low Pressure System . . . . . . . . 46

Low Pressure Adsorption . . . . . . . 53

The High Pressure System . . . . . . . 60

High Pressure Adsorption . . . . . . . . 64

Calculations .............. 69 
TABLE OF CONTENTS--Continued

Page

Adsorption of Water Vapor on Silver Iodide . . 85 The Adsorption of Methanol Vapor on Silver Iodide . . . . . . . . . . . 87

REFERENCES . . . . . . . . . . . . . . . 96 


\section{LIST OF TABLES}

Table

Page

1. AgI(I) Water Vapor Adsorption Data . . . . 35

2. AgI(II) Water Vapor Adsorption Data . . . . 36

3. Low Pressure System Constants . . . . . . . 52

- 4. Blank Low Pressure Adsorption Data . . . . 55

5. Low Pressure Adsorption Data . . . . . . . 57

6. High Pressure System Constants . . . . . 65

7. High Pressure Adsorption Data . . . . . . 67

8. Isosteric Heat of Adsorption

Low Pressure Data . . . . . . . . . . 73

9. Isosteric Heat of Adsorption High Pressure Data . . . . . . . . . . . 76

10. Differential Entropy of Adsorption Low Pressure Data . . . . . . . . . . . 79

11. Differential Entropy of Adsorption High Pressure Data 


\section{LIST OF ILLUSTRATIONS}

Figure

Page

1. Water Vapor Adsorption System . . . . . . . 31

2. Adsorption of Water Vapor on Silver Iodide . . 37

3. System for Determining the Effect of Mercury

Vapor on the Adsorption of Methano1 on Silver Iodide . . . . . . . . . . . . 39

4. Low Pressure Methanol Adsorption System . . . . 47

5. Low Pressure Blank Methano1 Adsorption Isotherms 56

6. Low Pressure Methanol Adsorption Isotherms . . 59

7. High Pressure Methanol Adsorption System . . 61

8. High Pressure Methanol Adsorption Isotherms . . 68

9. Adsorption Isosteres . . . . . . . . . 70

10. Isosteric Heats of Adsorption, Low Pressure Data . . . . . . . . . . 75

11. Isosteric Heats of Adsorption, High Pressure Data . . . . . . . . . . . 78

12. Differential Entropy of Adsorption, Low Pressure Data . . . . . . . . . . . 83

13. Differential Entropy of Adsorption, High Pressure Data . . . . . . . . . . 84 


\begin{abstract}
The Adsorption of Methanol Vapor on Silver Iodide Harry W. Edwards Ph. D. The University of Arizona 1966 Dissertation Director: M. L. Corrin
\end{abstract}

The adsorption of water vapor on two different preparations of silver iodide has been measured at $30^{\circ} \mathrm{C}$. AgI(I) was prepared by aqueous precipitation and contained a small amount of coprecipitated $\mathrm{NH}_{4} \mathrm{NO}_{3}$ as a contaminant. AgI(II) was prepared by the reaction of silver and iodine in vacuo with subsequent liquid ammonia treatment. The adsorption isotherm for $\operatorname{AgI}(I)$ is type III. The isotherm for $\mathrm{AgI}(\mathrm{II})$ is almost linear and does not fit into the Brunauer classification. At relative pressures exceeding 0.5 , the amount of water adsorbed per unit

- area is considerably greater for the contaminated material. The results indicate the very large effect on the surface properties of silver iodide caused by a small amount of surface contaminant. 
The adsorption of methanol vapor on $\mathrm{AgI}$ (II) was measured at $9.77^{\circ}, 19.79^{\circ}$ and $30.02^{\circ} \mathrm{C}$ over the pressure range 0.24 to $108 \mathrm{~mm}$. The isotherms do not fit into the Brunauer classification. The shape of the isotherms indicates the absence of three-dimensional clustering in the adsorbed phase. Differential heats and entropies of adsorption were calculated from the adsorption data.

The dependence of the differential heats and entropies of adsorption upon surface coverage reveals the dual nature of the silver iodide surface. Approximately $12 \%$ of the surface consists of higher energy sites located patch-wise on the surface. The remainder of the surface is made up of lower energy sites. 


\section{INTRODUCTION}

Formation of a Condensed. Phase from a Vapor

In a system sufficiently free of foreign contaminants, a gas, may be cooled well below the temperature at which the liquid and vapor coexist in equilibrium without the appearance of the condensed phase. In this state the vapor is said to be supersaturated with respect to the liquid and is a metastable phase. Even though the supercooled vapor is thermodynamically unstable with respect to the condensed phase, it may persist for an essentially indefinite period of time. The explanation for this phenomenon lies in the surface properties of the system. It is usually assumed that the new phase is generated from the supercooled vapor by nuclei which appear as tiny droplets. These droplets differ from the bulk liquid only in state of aggregation and serve as precursors of the bulk 1iquid. If we now examine the dependence of the free energy of a pure substance upon its state of subdivision, we will see that the above statement of homogeneous nucleation cannot be strictly correct. The Gibbs free energy 
function, G, for a one-component system consisting of the phase A, the vapor, and the phase B, one condensed aggregate, is given at a fixed temperature and total pressure by

$$
\begin{aligned}
& \mathrm{G}=\Sigma \mathrm{un}+\gamma_{\mathrm{A}} \\
& \mathrm{G}=\mathrm{u}_{\mathrm{A}} \mathrm{n}_{\mathrm{A}}+\mathrm{u}_{\mathrm{B}} \mathrm{n}_{\mathrm{B}}+\gamma_{\mathrm{A}}
\end{aligned}
$$

where

$$
\begin{aligned}
& \mathrm{n}_{\mathrm{A}}=\text { number of moles in phase } \mathrm{A} \\
& \mathrm{n}_{\mathrm{B}}=\text { number of moles in phase } \mathrm{B} \\
& \mathrm{u}_{\mathrm{A}}=\text { chemical potential of substance in phase } A \\
& \mathrm{u}_{\mathrm{B}}=\text { chemical potential of substance in phase } B \\
& \gamma=\text { surface free energy } \\
& \mathrm{A}=\text { surface area }
\end{aligned}
$$

By requiring that $n_{A}+n_{B}=$ constant, $d n_{A}=-d n_{B}$, and that for all possible equilibrium variations, $\mathrm{dG}=0$, the equilibrium state of the system may be determined.

$$
\begin{gathered}
d G=u_{A} d n_{A}+u_{B} d n_{B}+\gamma d A=0 \\
d G=\left(u_{B}-u_{A}\right) d n_{B}+\gamma d A=0 \\
u_{B}-u_{A}+\gamma\left(d A / d n_{B}\right)_{T, P}=0
\end{gathered}
$$

thus

$$
\mathrm{u}_{\mathrm{A}}-\mathrm{u}_{\mathrm{B}}=r\left(\mathrm{dA} / \mathrm{dn}_{\mathrm{B}}\right)_{\mathrm{T}, \mathrm{P}}
$$


Since $\left(d A / d n_{B}\right)_{T, P}$ must be greater than zero, equation (5) indicates that a vapor in equilibrium with its condensed phase of significant surface area is characterized by a chemical potential greater than that of the material in the condensed phase. When the surface area of the condensed phase becomes invariant with the amount of condensed phase present, the surface contribution disappears and the familiar condition of equilibrium is recovered, e.g., $u_{A}=u_{B}$.

Let us now consider the case of a spherical liquid droplet in equilibrium with its saturated vapor.

$$
\begin{aligned}
\mathrm{u}_{\mathrm{A}}-\mathrm{u}_{\mathrm{B}} & =r\left(\mathrm{dA} / \mathrm{dn}_{\mathrm{B}}\right)_{\mathrm{T}, \mathrm{P}} \\
\mathrm{A} & =4 \pi \mathrm{r}^{2} \\
\mathrm{dA} & =8 \pi \mathrm{rdr} \\
\mathrm{dn} \mathrm{n}_{\mathrm{B}} & =\mathrm{dV} / \mathrm{v}_{\mathrm{m}} \\
\mathrm{V} & =4 \pi \mathrm{r}^{3 / 3} \\
\mathrm{dV} & =4 \pi \mathrm{r}^{2} \mathrm{dr} \\
\mathrm{dA} / \mathrm{dn}_{\mathrm{B}} & =(\mathrm{dA} / \mathrm{dV}) \mathrm{V}_{\mathrm{m}}=2 \mathrm{~V}_{\mathrm{m}} / \mathrm{r}
\end{aligned}
$$

thus

$$
u_{A}-u_{B}=2 v_{m} \gamma / r
$$


It is convenient to express this result in terms of the fugacity which may be approximated by the vapor pressure.

$$
\ln \left(f_{A} / f_{B}\right)=2 V_{m} \gamma / R T r
$$

In the latter form this result is known as the Kelvin equation (W. Thomson, 1871) and predicts that the vapor pressure over a liquid droplet is larger than that over the plane-surfaced bulk liquid. Although this result has been accepted for many years, the Kelvin effect has only recently been experimentally verified (La Mer and Gruen, 1952): La Mer and Gruen equilibrated droplets of dioctyl phthalate with the vapor over solutions of dioctyl phthalate in toluene. By determining the fugacity of the solute as a function of drop size, the Kelvin equation was verified.

Although the use of the bulk 1iquid surface tension in the Kelvin equation for calculating the vapor pressures over very small droplets has been seriously questioned, by Reiss (1952) and by Buff (1951) for example, the dependence of the surface tension upon drop size has never been experimenta1ly determined. 
The Kelvin effect poses a problem in explaining the mechanism of condensation of a liquid from a vapor. The relation indicates that the tiny embryo droplets which lead to the formation of the bulk 1iquid would be unstable with respect to the vapor and therefore should immediately evaporate. The formation of the liquid at the equilibrium vapor pressure or even well above it would appear to be impossible. The energy barrier to formation of a condensed phase from a vapor may be evaluated by calculating the work required to form the new phase. Consider the following process:

$$
\begin{aligned}
& \left(n_{A}+n_{B}\right)_{\text {vapor }}=\left(n_{A}\right)_{\text {vapor }}+\left(n_{B}\right)_{\text {condensed }} \\
& \Delta G=G_{\text {final }}-G_{\text {initial }} \\
& \Delta G=n_{A} u_{A}+n_{B} u_{B}+\gamma_{A}-\left(n_{A}+n_{B}\right) u_{A} \\
& \Delta G=\left(u_{B}-u_{A}\right) n_{B}+\gamma_{A}
\end{aligned}
$$

From equation (5) we see that

$$
\mathrm{u}_{\mathrm{A}}-\mathrm{u}_{\mathrm{B}}=\gamma\left(\mathrm{dA} / \mathrm{dn}_{\mathrm{B}}\right)_{\mathrm{T}, \mathrm{P}}=\gamma \overline{\mathrm{A}}_{\mathrm{C}}
$$

where $\overline{\mathrm{A}}_{\mathbf{C}}$ denotes the critical value of the partial molar surface area. Substituting $-\gamma \bar{A}_{c}$ for $\left(u_{B}-u_{A}\right)$ yields

$$
\Delta G=-\gamma \bar{A}_{c} n_{B}+\gamma \mathrm{A}
$$

Equation (9) takes on physical significance if we assume that the condensed phase takes the form of a 
spherical drop in the case of a liquid or a regular polyhedron in the case of a solid. Making this assumption, we find

$$
\begin{aligned}
& \mathrm{V}=\mathrm{kz} \mathrm{z}^{3} \\
& \mathrm{~A}=\mathrm{cz} \mathrm{z}^{2}
\end{aligned}
$$

where $z$ is a size parameter and $k$ and $c$ are constants.

$$
\begin{aligned}
& \overline{\mathrm{A}}_{\mathrm{c}}=(2 \mathrm{c} / 3 \mathrm{kz} \mathrm{c}) \mathrm{V}_{\mathrm{m}} \\
& \Delta \mathrm{G}=-\gamma\left(2 c \mathrm{~V}_{\mathrm{m}} / 3 \mathrm{kz} \mathrm{z}_{\mathrm{c}}\right) \mathrm{n}_{\mathrm{B}}+\gamma \mathrm{A} \\
& \Delta \mathrm{G}=-\gamma\left(2 c / 3 \mathrm{kz}_{\mathrm{c}}\right) \mathrm{V}+\gamma_{\mathrm{A}} \\
& \Delta \mathrm{G}=-\gamma(2 \mathrm{c} / 3 \mathrm{kz} \mathrm{c}) \mathrm{kz}{ }^{3}+\gamma \mathrm{cz}^{2} \\
& \Delta G=\gamma_{c z^{2}}\left(1-2 z / 3 z_{c}\right)
\end{aligned}
$$

The derivative $(\partial \Delta G / \partial z)$ becomes zero when $z=z_{c}$. Therefore,

$$
\Delta \mathrm{G}_{\max }=\gamma \mathrm{cz}^{2} / 3=\gamma \mathrm{A} / 3
$$

Equation (10) indicates that condensed aggregates smaller than the critical size are unstable with respect to the vapor and would re-evaporate. Aggregates larger than the critical size are unstable with respect to the bulk material and therefore would continue to grow until $\mathrm{u}_{\mathrm{A}}$ becomes equal to $\mathrm{u}_{\mathrm{B}}$. Equation (10) has been discussed by Frenkel (1946) for the case of the spherical liquid drop. Although the quantity $\gamma \mathrm{A} / 3$ was first obtained by 
Gibbs (1878) as the work of forming a "fluid of different phase within any homogeneous fluid," its importance as a key to the problem of nucleation was not recognized until many years later by Volmer (1929).

The question now arises as to how a system may gain this amount of free energy $(\gamma \mathrm{A} / 3)$ at constant temperature and pressure and thus undergo a spontaneous phase transition. There are essentially two ways of answering this question. The first way is to recognize the statistical nature of thermodynamics. Even at equilibrium fluctuations about the equilibrium state occur such that at any time, a smal1 number of embryo aggregates might temporarily and spontaneously form. Calculations show, however, that a very high degree of supersaturation is required to produce sufficient nuclei for appearance of the condensed phase. The second way is to introduce a foreign nucleus into the vapor which provides a surface upon which condensation is energetically favorable. It is probable that the second mechanism accounts for the majority of condensation processes in ordinary systems, e.g., those in which no special effort is made to free the system of foreign contaminants. 
Let us now examine the problem of bringing about the formation of a condensed phase from a supercooled vapor by means of the addition of an appropriate nucleant. We recall that even though the supercooled vapor is energetically unstable with respect to the condensed phase, condensation does not occur until the degree of supersaturation becomes high or the system undergoes a perturbation. If this perturbation takes the form of the addition of a foreign substance, the resulting process of condensation is termed heterogeneous nucleation. An understanding of the mechanism of heterogeneous nucleation requires a knowledge of how the addition of the foreign substance lowers the energy barrier to condensation provided by the Kelvin effect.

Let us assume that the initial step in the process of the heterogeneous nucleation of a vapor by a solid nucleant involves concentration of vapor at the surface of the solid. The spontaneous adsorption of a gas on a solid results from an interaction between the solid and the gas such that the free energy of the system is decreased by the concentration of gas at the gas-solid interface. The function of the solid in the process of heterogeneous 
nucleation is thus to provide an energetically favorable alternative to droplet formation as the precursor of the condensed phase. This alternative is the nucleant particle upon which is adsorbed a film of vapor. Further condensation of vapor upon the film-covered nucleant particle is now energetically favorable and formation of the bulk condensed phase may proceed.

Even though it is not here suggested that this simple picture of heterogeneous nucleation is complete, the treatment is useful in providing a line of attack on the problem at hand. It is apparent that heterogeneous nucleation is a surface phenomenon and that an understanding of the surface properties of a nucleant is needed in selecting an effective nucleant for a given vapor.

\section{Adsorption of a Gas on a Solid}

A particularly informative and experimentally accessible method for studying a solid surface is the measurement of adsorption isotherms. When a gas is allowed to interact with a solid surface, the gas tends to concentrate at the surface of the solid. This process is termed adsorption. The distribution of gas between the surface phase and the gas phase is governed by the nature 
and extent of the solid surface, the nature of the gas, and the temperature and pressure of the system. By application of the appropriate thermodynamic relationships to the adsorption data, the energetics of the interaction may be obtained.

The first exact treatment of surface thermodynamics was given by Gibbs. He represented the extensive thermodynamic functions for the surface in terms of excess functions. For a given extensive thermodynamic variable, $\mathrm{x}$,

$$
\mathrm{X}_{\mathrm{S}}=\mathrm{X}-\mathrm{x}_{\mathrm{A}}-\mathrm{x}_{\mathrm{B}}
$$

where $X_{S}$, the excess function, represents the difference in the extensive property between that for the real system, $\mathrm{X}$, and that calculated for a hypothetical system in which the phases $A$ and $B$ are completely uniform up to the dividing surface, $\left(x_{A}+x_{B}\right)$. In the case of the physical adsorption of a gas on a solid, it is generally assumed that the solid serves only as a perturbing support for the surface phase such that the chemical potential of the solid remains unchanged throughout the course of the adsorption process. For this system the surface excess of the adsorbent vanishes and the surface excess of the adsorbate is equal to the amount adsorbed. 
Severa1 authors have made major contributions to the understanding of the thermodynamics of surfaces since the time of Gibbs. The subject of the thermodynamics of gas adsorption is reviewed by Hill (1952) and by Everett (1957), for example. Only the functions pertinent to this investigation are presented here. Making the assumptions stated in the preceding paragraph, one may write for a differential change in the energy of the adsorbed phase

$$
\mathrm{dE}_{\mathrm{S}}=\operatorname{TdS}_{\mathrm{S}}-\phi \mathrm{dA}+\mathrm{u}_{\mathrm{s}} \mathrm{dn}_{\mathrm{s}}
$$

where $\phi=\gamma_{0}-\gamma$. From this combined statement of the first and second laws for the surface phase and the usual approximations that the volume of the surface phase is negligible in comparison with the volume of the gas phase, and that the unadsorbed gas may be treated as an ideal gas, two different heat functions may be derived (Hi11 1952).

$$
(\mathrm{d} \ln \mathrm{p} / \mathrm{dT})_{\mathrm{n}_{\mathrm{S}}}=\mathrm{q}_{\mathrm{st}} / \mathrm{RT}^{2}
$$

where

$$
\mathrm{q}_{\mathrm{St}}=\mathrm{H}_{\mathrm{g}}-\overline{\mathrm{E}}_{\mathrm{S}}=\mathrm{T}\left(\mathrm{S}_{\mathrm{g}}-\overline{\mathrm{S}}_{\mathrm{s}}\right)
$$

The quantity $\mathrm{q}_{\mathrm{st}}$ is termed the isosteric heat of adsorption and is a partial molar differential quantity. The second heat of adsorption is given by

$$
(\mathrm{d} \ln \mathrm{p} / \mathrm{dT})_{\phi}=\mathrm{q}_{\phi} / \mathrm{RT} \mathrm{T}^{2}
$$


where

$$
\mathrm{q}_{\phi}=\mathrm{H}_{\mathrm{g}}-\mathrm{E}_{\mathrm{S}}-\phi \mathrm{A} / \mathrm{n}_{\mathrm{S}}=\mathrm{T}\left(\mathrm{S}_{\mathrm{g}}-\mathrm{S}_{\mathrm{S}}\right)
$$

The quantity $\mathrm{q}_{\phi}$ is a molar integral heat of adsorption and requires that $\phi$ be known for its evaluation. The spreading pressure, $\phi$, may be calculated from a form of the Gibbs adsorption isotherm, namely

$$
\mathrm{d} \phi=\operatorname{RT}\left(\mathrm{n}_{\mathrm{s}} / \mathrm{A}\right) \mathrm{dln} \mathrm{p}
$$

Accurate integration of the Gibbs equation requires that isotherm data be taken at very low coverages; integral quantities are rarely obtained in practice due to the experimental difficulties associated with the measurement of adsorption isotherms at very low coverages. It should be pointed out, however, that both heat functions may be obtained from calorimetric data but the construction of a suitable calorimeter for the measurement of heats of adsorption on very low specific area solids is a very difficult problem due to the small quantity of heat liberated on adsorption.

The adsorption process may generally be classified in one of two categories, depending on the magnitude of the energy of interaction between the gas and the solid. If the heat of adsorption is of the same order of 
magnitude as the heat of condensation of the adsorbate, the process is termed physical adsorption. If the heat of adsorption is of the same order of magnitude as the heat of formation of a chemical bond, the process is termed chemisorption. The systems under consideration in this investigation involve physical adsorption only. Although the distinction between the two types of adsorption is not always clear-cut, a11 adsorption processes are exothermic. According to Brunauer (1945), there are five principal types of physical adsorption, as characterized by the shape of the adsorption isotherm. This distinction is useful in a qualitative sense only since many adsorption isotherms may not be classified in this manner.

An important parameter in characterizing adsorption systems is the volume of gas required to complete the monolayer. Although the quantity $V_{m}$ cannot be obtained from thermodynamics, Brunauer, Emmett and Teller (1938) have derived an equation of great practical utility from a consideration of the detailed mechanism of adsorption which permits $V_{\mathrm{m}}$ to be evaluated directly from adsorption data. Despite severe criticism on theoretical grounds (Young and Crowe11 1962, for example) the B.E.T. method is the most 
widely used technic for evaluating surface areas of solids. Experimental measurements of the amount of gas adsorbed as a function of pressure and temperature constitute the data of adśorption. Adsorption isotherms, e.g., $\mathrm{v}_{\text {ads }}=\mathrm{f}(\mathrm{p})_{\mathrm{T}}$, are essentially graphical representations of the change in free energy for the adsorption process as a function of surface coverage. A family of adsorption isotherms provides the data for calculation of differential heats and entropies of adsorption by means of a form of the Clausius-Clapeyron equation. Integral thermodynamic functions are in practice considerably more difficult to obtain since the complete isotherms are required. The differential functions are, however, quite useful in characterizing the nature of the solid surface and estimating the degree of adsorbate-adsorbate lateral interaction. A statistical thermodynamical interpretation of the interaction requires the use of the integral functions.

There are essentially two commonly used technics for obtaining adsorption data. By means of the gravimetric . method, the amount of gas taken up by the adsorbent may be obtained by measuring the elongation of a calibrated spring from which the adsorbent sample is suspended. The method 
is limited only by the sensitivity of the spring; the spring may be any device for measuring changes in weight. Electrobalances with microgram sensitivities which may be mounted in vacuum systems are now commonly used to obtain adsorption isotherm data.

Use of the volumetric method for obtaining adsorption isotherm data involves determining the temperature, pressure and volume of a dose of adsorbate. The dose is then allowed to interact with the adsorbent. After the temperature, pressure and volume of the adsorption system have attained constant values, the number of moles of adsorbate present in the gas phase is calculated. The amount of adsorbate on the surface is given by the number of moles present initially less the number of moles remaining in the gas phase. By carefully keeping account of the location and amount of adsorbate present in the system, successive doses may be introduced and the entire adsorption isotherm determined. The volumetric method becomes severely handicapped when the amount of gas adsorbed is much smaller than the total amount of gas present. In this case, the amount adsorbed is obtained as a small difference between two relatively large numbers. For this reason; the volumetric 
method is not well suited for measurements on materials of low specific surface areas. In order to minimize this difficulty, systems of low dead-space volume are utilized for measurements on these materials.

\section{Silver Iodide as a Nucleant for Water Vapor}

Widespread interest in silver iodide as a nucleant for supercooled water vapor stems from the report by Vonnegut (1947) that finely divided silver iodide in the form of a smoke produces ice crystals from supercooled water vapor at temperatures below $-4^{\circ} \mathrm{C}$. In his search for a nucleating material for supercooled clouds, Vonnegut selected silver iodide on the basis of its close resemblance to ice in crystal structure. Schaefer (1949) observed that the greater the deviation of the crystal parameters of the nucleant from those of ice, the greater the degree of supercooling required to initiate ice crystalization. Wylie (1953) found that no substance other than ice itself nucleates water at temperatures close to $0{ }^{\circ} \mathrm{C}$. In a review of the subject of nucleation theory, La Mer (1952) commented as follows: "Silver iodide differs from ice only in minor deviations in the parameters 
of the crystal lattice, yet these minor differences are sufficient to require that water be supercooled from $4^{\circ}$ to $6^{\circ} \mathrm{C}$. to initiate crystallization." Proponents of the epitaxy concept, for which the above works constitute some of the major evidence, argue that water vapor is somehow tricked by the ice-1ike crystal structure of silver iodide such that ice crystal formation on the silver iodide particle is spontaneous. Largely because the epitaxy argument has not been substantiated by experimental evidence, it has fallen from favor and most investigators now recognize the importance of the surface properties of the nucleant in the process which leads to the formation of the new phase. It should be pointed out, however, that cloud physicists still regard silver iodide as the best cloud seeding material yet found. Mason (1957), who presented a thorough discussion of nucleation as a surface phenomenon in his treatment of cloud physics, observed that silver iodide functions as a more effective nucleant for water vapor than any other material yet tested. It is therefore apparent that at least a partial explanation for the efficiency of silver iodide as a nucleant for supercooled water vapor lies in an 
understanding of the surface properties of silver iodide.

It has long been known that silver iodide sols are unstable in water; in the titration of iodides with silver nitrate, silver iodide precipitates out as soon as a slight excess of silver nitrate has been added. Although sol coagulation is a complex phenomenon, one might well ask how a material with an apparently hydrophobic surface can function as an effective nucleant for water vapor. Before this question can be answered, it is apparent that the thermodynamics of the interaction between water vapor and silver iodide must be known. As it has been pointed out earlier in this work, the information may be obtained from adsorption data.

The adsorption of water vapor on silver iodide has been measured by several investigators. By a volumetric technique, Coulter and Candela (1952) measured type III adsorption at $16.0^{\circ}, 34.0^{\circ}$ and $50.0^{\circ} \mathrm{C}$ with isosteric heats less than the heat of condensation of water. The authors noted that the presence of an unknown surface impurity on their silver iodide sample cast some doubt on their results. By means of a gravimetric technique, Birstein (1955) measured type III adsorption between $-20^{\circ}$ and $+26^{\circ} \mathrm{C}$ 
with isosteric heats greater than the heat of condensation. He reported that his sample of silver iodide accepted in excess of 150 monolayers before the saturation pressure was reached. In contrast, Karasz, Champion and Halsey (1956) reported that they were unable to detect the adsorption of any water vapor on silver iodide at $-45.2^{\circ} \mathrm{C}$ and concluded that the surfaces of ice and silver iodide were energetically incompatible. Type II adsorption at $-20^{\circ}$ to $+20^{\circ} \mathrm{C}$ was measured by Moskvitin, Dubinin and Sakharov (1959) with a maximum water adsorption of slightly more than three monolayers at a relative pressure of approximately 0.8. Isosteric heats on the order of the heat of 1iquefaction of water were reported. Apparent discontinuities in their adsorption isosteres were interpreted in terms of a phase transition at $0^{\circ} \mathrm{C}$. Zettelmoyer, Tcheurekdjian and Chessick (1961) compared the B.E.T. water and nitrogen specific surface areas for a number of silver iodide preparations. These authors interpreted the ratio of the two areas as a measure of the hydrophilic character of the silver iodide surface. Since the ratios were always much less than unity, it was stated that the results supported the contention that the silver iodide surface was rather 
hydrophobic. An adsorption mechanism involving localized cluster formation was suggested as an explanation for the nucleating properties of silver iodide. Hall and Tompkins (1962) measured the adsorption of water vapor on silver iodide between $-45^{\circ}$ and $-25^{\circ} \mathrm{C}$ in the monolayer region. Isosteric heats of adsorption considerably less than the heat of condensation were reported; the variation in $\mathrm{q}_{\mathrm{st}}$ with coverage agreed in a qualitative manner with a curve calculated on the basis of an ideally uniform adsorbent surface. The authors stated that the results confirmed that the silver iodide surface was hydrophobic and that the nucleating efficiency of silver iodide is probably associated with the ease of cluster formation. Zettlemoyer, Tcheurekdjian and Hosler (1963) assert that the nucleating properties of silver iodide result from the optimum proportion of hydrophilic to hydrophobic sites present on the surface, as determined by the ratio of B.E.T. water to nitrogen surface areas. The authors suggested that the hydrophilic sites must be randomly distributed over the surface, rather than occurring in patches. Attempts were made to produce synthetic nucleants with the optimum ratio but none of the 
materials performed better than silver iodide. In 1964 , Tcheurekdjian, Zettlemoyer and Chessick measured the adsorption of water vapor on silver iodide at four temperatures between $-15.8^{\circ}$ and $+20^{\circ} \mathrm{C}$. Heats of adsorption below the heat of 1iquefaction were reported and the results were interpreted in terms of a largely hydrophobic silver iodide surface with a few scattered hydrophilic sites at which cluster formation occurred. However, the authors found that the fraction of hydrophilic sites varied from sample to sample. This they attributed to variations in surface concentrations of an unspecified impurity. At this point it is appropriate to note that very little agreement exists between the various authors concerning the nature of the interaction between water vapor and silver iodide. It is interesting to note, however, that all of the silver iodide samples investigated thus far were products of aqueous precipitation; two groups reported that their results suggested the presence of surface contaminants. In 1963, Corrin and Storm reported that all samples of silver iodide prepared by solution precipitation were contaminated to some extent. This result casts considerable doubt on the validity of 
measurements of water adsorption made on silver iodide samples prepared by aqueous precipitation. It is clear that the discrepancies in the water adsorption measurements may be due to the presence of varying amounts of surface contaminants. It is also apparent that these measurements may not be typical of the uncontaminated silver iodide surface. This conclusion is further supported by the work of Tompkins, Muss and Pearson (1963) who found that the amount of water vapor adsorbed by a series of AgI-KI mixtures was highly dependent upon the amount of KI present.

From the work of Corrin and Storm (1963) it appears that silver iodide is not a particularly suitable material for investigation in the surface chemistry 1aboratory. It was found that silver iodide sinters rapidly, even at moderate temperatures. Gentle grinding was found to cause a drastic reduction in surface area. Corrin and Storm also reported that they were unable to prepare silver iodide samples of reproducible surface properties by precipitation from aqueous solution. The highest specific surface area obtained by this method was $2 \mathrm{~m}^{2} / \mathrm{g}$. These findings, coupled with the well known light sensitivity of silver 
iodide, indicate that silver iodide is a difficult material to handle in the laboratory and may in part account for some of the discrepancies in water adsorption that have been reported.

It is apparent that a new approach to the problem of characterizing the surface properties of silver iodide is needed. A major part of the problem is the preparation of a contaminant-free material with stable and reproducible surface properties. It is therefore appropriate that the question of how silver iodide may function as an effective nucleant for water vapor be set aside and the subject of this investigation, the characterization of the surface properties of contaminant-free silver iodide, be considered in detail. 


\section{STATEMENT OF THE PROBLEM}

The subject of this dissertation is the characterization of the surface properties of silver iodide. The method of approach is to determine the energetics of the interaction of a selected gas with the silver iodide surface. This is done by measuring the adsorption of the gas on silver iodide as a function of temperature and pressure. The adsorption at a single temperature provides a measure of the free energy of the interaction. A family of adsorption isotherms provides data for calculation of the differential enthalpy and entropy of adsorption. By using an appropriate gas as a probe, the thermodynamic data may be interpreted in terms of the surface structure of silver iodide.

In order for the results of the investigation to be truly representative of the silver iodide surface, it is essential that the study be carried out on a material of reproducible surface properties. Previous adsorption studies on silver iodide prepared by aqueous precipitation indicated the need for such a material. The widely 
differing results reported by previous investigators are highly suggestive of a major effect upon the surface properties of silver iodide by the contaminants which are a1ways associated with the precipitated material. Since this effect has not been firmly established, it is apparent that an essential part of this investigation must involve an evaluation of the effect of coprecipitated impurities upon the adsorptive properties of silver iodide. A material free of coprecipitated ionic impurities has been prepared and made available for this investigation. The preliminary part of this investigation therefore involves an experiment designed to detect any gross difference in the behavior of two different preparations of silver iodide toward water vapor. The first material was prepared by the usual method of solution precipitation and the second material was prepared by the direct reaction of silver and iodine. The results of the preliminary investigation were reported earlier by Corrin, Edwards and Nelson (1964) and constitute part of the work upon which this dissertation is based.

The major part of this investigation deals with the interaction of methanol vapor with the uncontaminated 
silver iodide surface. Methanol was chosen as the adsorbate for two reasons. If the silver iodide surface is homoenergetic, as was suggested by Hall and Tompkins (1962), the heat of adsorption of a polar adsorbate would be relatively independent of coverage until the monolayer region is approached. If the polar adsorbate were water vapor, however, the heat of adsorption might be highly dependent upon coverage owing to the strong hydrogen bonding interaction between adsorbed water molecules. The effect of the homoenergetic surface would be masked and the heat curve might easily be interpreted as that of a heteroenergetic surface. If, on the other hand, the silver iodide surface is heteroenergetic, as was suggested by Tcheurekdjian, Zettlemoyer and Chessick (1964), the heat of adsorption would be expected to decrease with increasing coverage. The question now arises as to whether the higher energy sites are located in patches on the surface or are randomly distributed over the surface. This question would be very difficult to answer using water vapor as the adsorbate because of the added complication of the interaction due to strong adsorbate-adsorbate hydrogen bonding on the surface. It is clear that 
the use of water vapor as a probe would not give an unequivocal picture of the silver iodide surface. Methanol was selected because it is like water in having the polar hydroxyl function but unlike water in the extent of adsorbate-adsorbate hydrogen bonding that one might expect in the adsorbed phase. The possibility of stacking effects can be essentially ruled out with methanol at less than monolayer coverage whereas this cannot be done for water.

Aside from being the simplest straight-chain a1cohol, methanol was selected because of the temperature range in which the adsorption was to be measured. For a given adsorbate pressure, lateral interactions in the adsorbed phase are least at low coverages and high temperatures. Since Corrin and Storm (1963) reported that silver iodide sinters appreciably at temperatures above $50^{\circ} \mathrm{C}$, the highest temperature at which the adsorption could be measured was limited to a temperature slightly above room temperature. Methanol was selected because its vapor pressure is sufficiently high at room temperature to permit the addition of large doses of adsorbate to the adsorption system without condensation in the system. The 
relatively large amount of unadsorbed gas in the adsorption system at higher temperatures requires a large dosing capacity, particularly for adsorbents of low specific surface area. 


\section{EXPERIMENTAL}

The Adsorption of Water Vapor on Silver Iodide Materials

The silver iodide designated $\mathrm{Ag}(\mathrm{I})$ was identical to that studied by Corrin and Storm (1963) which was prepared by the reaction between $\mathrm{AgNO}_{3}$ and $\mathrm{NH}_{4} \mathrm{I}$ in aqueous solution. $\operatorname{AgI(I)}$ was known to be contaminated with $\mathrm{NH}_{4} \mathrm{NO}_{3} \cdot$ The material designated $\mathrm{AgI}$ (II) was prepared by J. A. Nelson by the direct reaction of silver and iodine in vacuo with subsequent dissolution and filtration in liquid ammonia. The ammonia was then pumped off to yield the purified product. X-ray diffraction patterns for the two materials were identical. The specific surface areas for the two materials were determined by application of the B.E.T. relation to krypton adsorption isotherm data at $76.7^{\circ} \mathrm{K}$. The specific surface area of $\mathrm{AgI}(\mathrm{I})$ was $0.38 \mathrm{~m}^{2} / \mathrm{g}$ and that of $\mathrm{AgI}$ (II) was $0.35 \mathrm{~m}^{2} / \mathrm{g}$. The vapor pressure of the sample of de-ionized and distilled water was measured at two temperatures and the results compared with the literature values. Since the experimentally 
determined vapor pressures were within $0.5 \%$ of the handbook values, the water sample was considered sufficiently pure for this investigation. The helium used to determine the volume of the adsorption system was obtained from the Air Reduction Company, Inc, in a one-liter Pyrex glass flask fitted with a break seal. The manufacturer specified that the helium contained no detectable impurities as determined by a mass spectrometer with a lower limit of detectability of five parts per million.

\section{Apparatus}

A conventional volumetric system designed to detect gross differences in the water adsorption of $\mathrm{AgI}(\mathrm{I})$ and $\mathrm{AgI}$ (II) was used to measure the amount of water vapor adsorbed as a function of pressure at constant temperature. This system is shown in Figure 1 . A doser constructed of precision-bore tubing was used to meter out the water vapor. A wide-bore mercury manometer and cathetometer were used to determine pressures. Pressures were measured to $\pm 0.02 \mathrm{~mm}$. The adsorbent samples were thermostated at $30^{\circ} \mathrm{C}$ by means of a regulated water bath. The system deadspace volumes were determined by expanding measured doses 


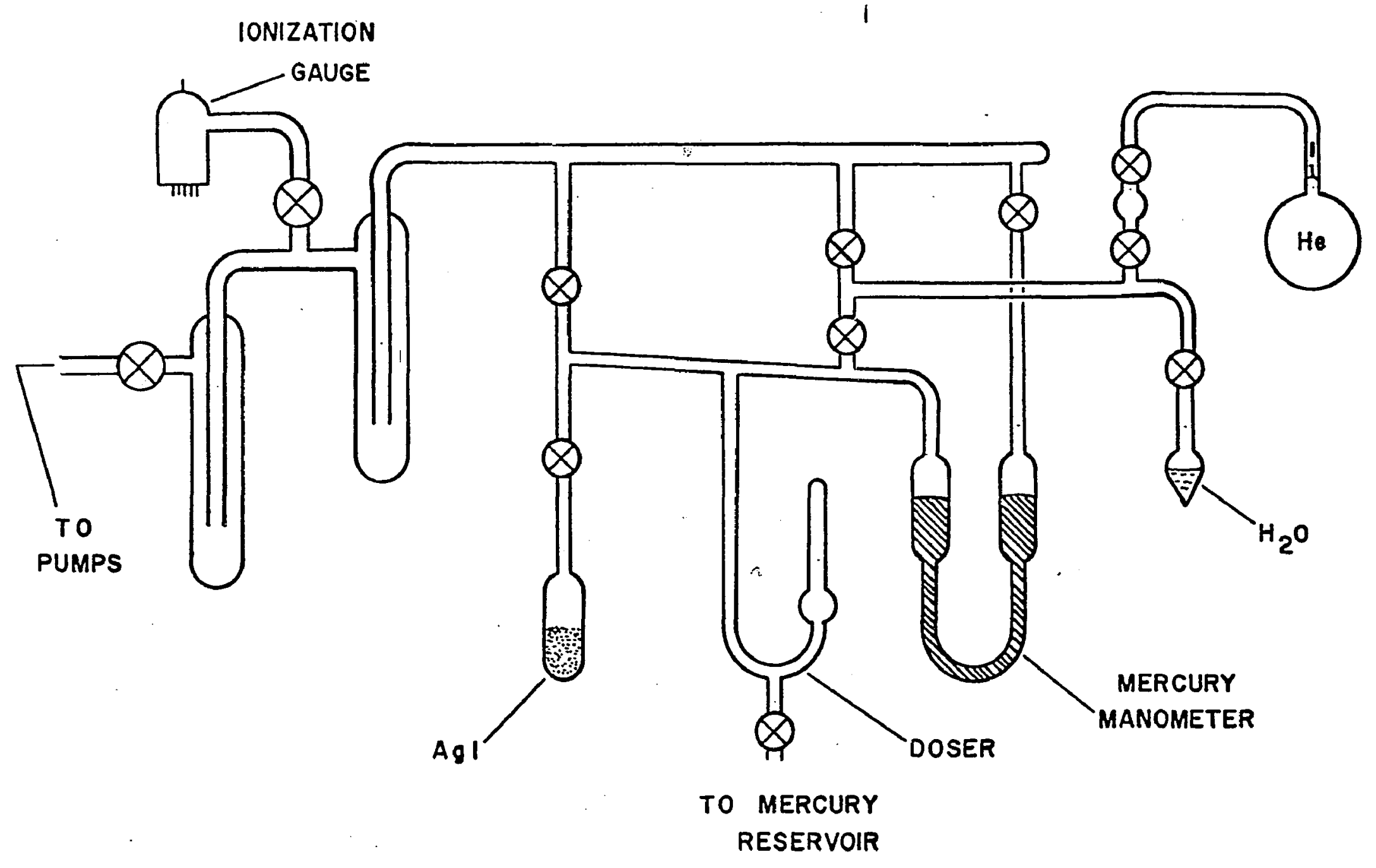

FIGURE 1. WATER VAPOR ADSORPTION SYSTEM 
of non-adsorbing helium into the system. The perfect gas equation was used in all P-V-T calculations. Air was removed from the bulb containing the water by repeatedly cooling the bulb to liquid nitrogen temperature and pumping while the bulb warmed. The heart-shaped bulb used to contain the water sample was employed to prevent cracking as the bulb warmed during the outgassing procedure. The system was then outgassed at room temperature until the system pressure remained constant at $10^{-6} \mathrm{~mm}$ as measured by the Veeco ionization gauge.

Adsorption Measurements

Adsorption measurements were carried out jointly with J. A. Nelson. The adsorption isotherms were determined as follows: The temperature, pressure and volume of a dose of water vapor were measured. The number of moles in the dose was calculated using the perfect gas equation. The dose was then allowed to interact with the silver iodide. A period of at least six hours was allowed for the pressure in the system to attain a constant value. The equilibrium pressure and temperature were then measured and the number of moles of water vapor remaining in 
the gas phase was calculated. The amount of water vapor adsorbed was given by the difference between the number of moles present initially and the number of moles remaining in the gas phase. The stopcock connecting the adsorption bulb to the system was then closed and the system pumped out. The number of moles remaining in the system was calculated as the number of moles present initially less the number of moles pumped out. A second dose was then measured out and expanded into the system. The adsorption bulb stopcock was opened and the second dose allowed to equilibrate with the adsorbent. The temperature and pressure were then measured and the number of moles of unadsorbed gas calculated. The number of moles adsorbed was given by

$$
\mathrm{n}_{\text {ads }}(2)=\mathrm{n}_{\mathrm{r}}(1)+\mathrm{n}_{\mathrm{d}}(2)-\mathrm{n}_{\mathrm{g}}(2)
$$

where

$$
\begin{aligned}
& n_{\text {ads }}=\text { number of moles adsorbed } \\
& n_{r}=\text { number of moles remaining in system } \\
& n_{d}=\text { number of moles in dose } \\
& n_{g}=\text { number of moles unadsorbed at equilibrium }
\end{aligned}
$$


The expression may be generalized for succeeding doses as follows:

$$
n_{\text {ads }}(i)=n_{r}(i-1)+n_{d}(i)-n_{g}(i)
$$

where $i$ is the index of the dose. For large doses the entire system, less the adsorption bulb, was used as a doser.

By the method described above, the adsorption of water vapor was measured for $\mathrm{AgI}(\mathrm{I})$ and $\mathrm{AgI}(\mathrm{II})$. A blank adsorption isotherm was also measured to facilitate correction of the silver iodide adsorption data for the water vapor taken up by the glass adsorption apparatus. The blank adsorption isotherm was essentially type I, according to the Brunauer classification. The correction for the blank adsorption was made by drawing a smooth curve through the blank isotherm points and subtracting the blank adsorption point by point from the observed adsorption. The adsorption data are given in Table 1 and Table 2 as the corrected number of moles of water adsorbed as a function of relative pressure. In Figure 2, the adsorption isotherms are shown. A gross difference in the behavior of the two materials is apparent. 
TABLE 1

AgI(I) Water Vapor Adsorption Data

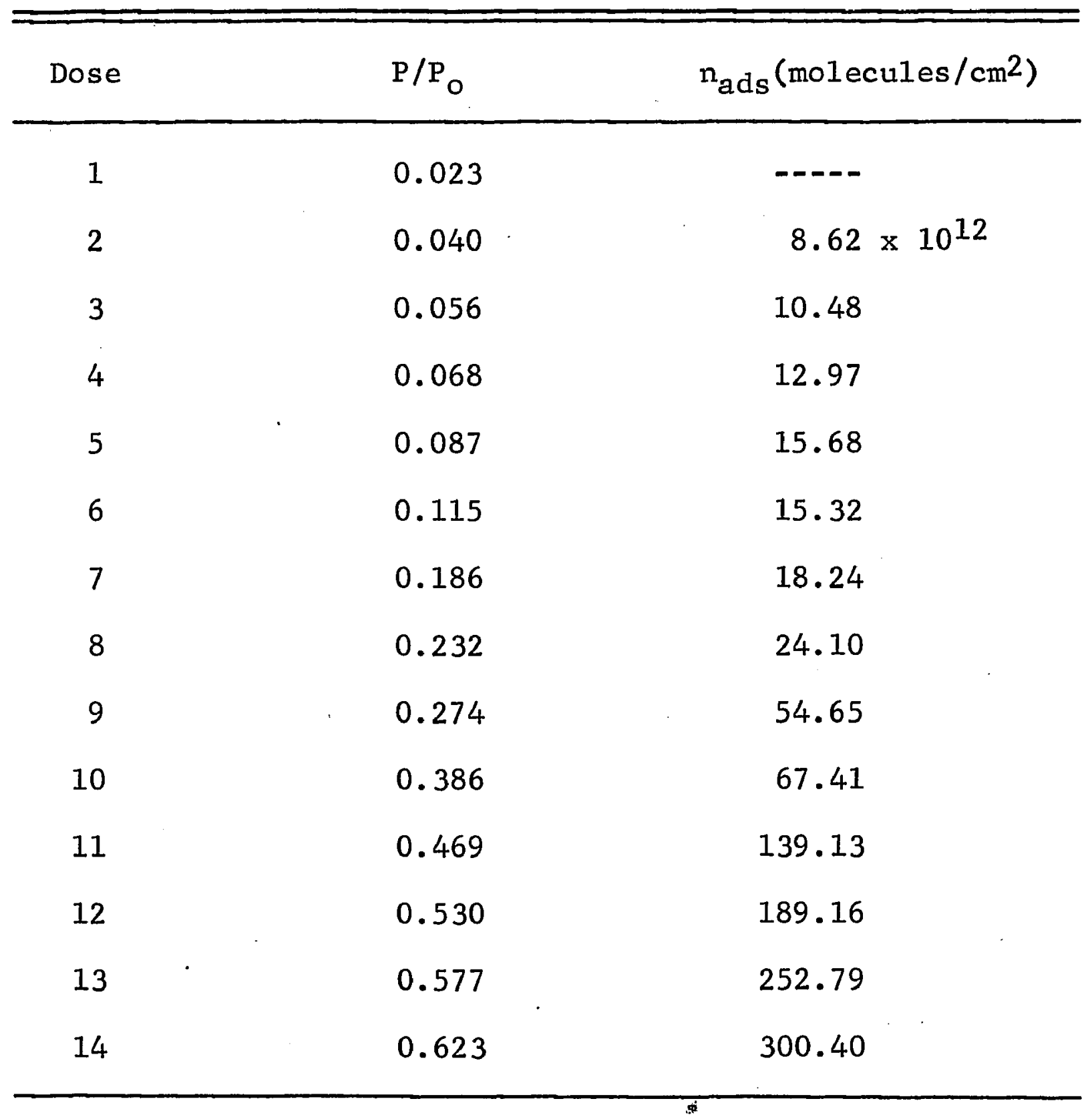


TABLE 2

AgI(II) Water Vapor Adsorption Data

\begin{tabular}{|c|c|c|}
\hline Dose & $\mathrm{P} / \mathrm{P}_{\mathrm{O}}$ & $\mathrm{n}_{\text {ads }}\left(\right.$ molecules $/ \mathrm{cm}^{2}$ ) \\
\hline 1 & 0.021 & $\ldots-$. \\
\hline 2 & 0.036 & $3.10 \times 10^{12}$ \\
\hline 3 & 0.050 & 22.93 \\
\hline 4 & 0.077 & 22.55 \\
\hline 5 & 0.091 & 24.98 \\
\hline 6 & 0.111 & 29.14 \\
\hline 7 & 0.193 & 32.46 \\
\hline 8 & 0.242 & 44.20 \\
\hline 9 & 0.286 & 59.49 \\
\hline 10 & 0.334 & 75.40 \\
\hline 11 & 0.390 & 81.98 \\
\hline 12 & 0.409 & 89.69 \\
\hline 13 & $0.451^{\circ}$ & 88.56 \\
\hline 14 & 0.501 & 90.52 \\
\hline 15 & 0.536 & 125.86 \\
\hline 16 & 0.624 & 132.23 \\
\hline 17 & 0.691 & 144.10 \\
\hline
\end{tabular}




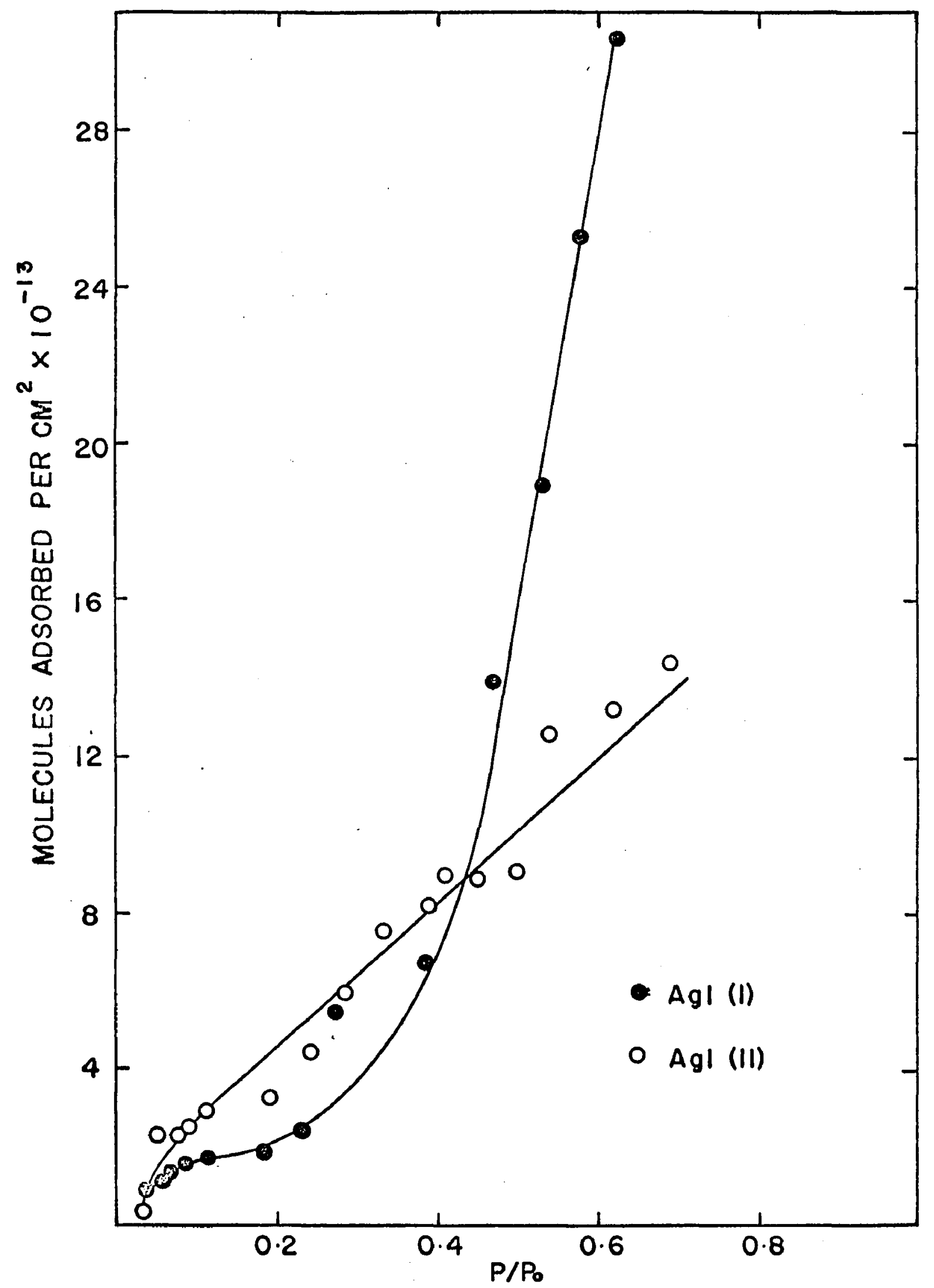

FIGURE 2- ADSORPTION OF WATER VAPOR ON SILVER IODIDE 


\section{Effect of Mercury Vapor on Methanol Adsorption}

Ordinary stopcock lubricant could not be used in the methanol adsorption system due to the solubility of methanol in the lubricant. The use of mercury float valves was considered the most reliable alternative to the use of lubricated vacuum stopcocks. An apparatus was then constructed to determine the effect of the presence of mercury vapor on the adsorption of methanol on silver iodide.

\section{Apparatus}

The system shown in Figure 3 was used to determine the effect of mercury vapor on methanol adsorption. A mercury diffusion pump backed by a conventional rotary oil pump was used to evacuate the system. The pumps were joined to the system through a trap maintained at liquid nitrogen temperature. A Veeco ionization gauge was used to monitor the rate of outgassing. A type L-252C thermistor gauge supplied by Gulton Industries, Inc., was used as the primary pressure measuring device. The thermistor element constituted one arm of a Wheatstone bridge circuit whose off-balance voltage was measured with a Leeds and Northrup potentiometric recorder. The off-balance signal 


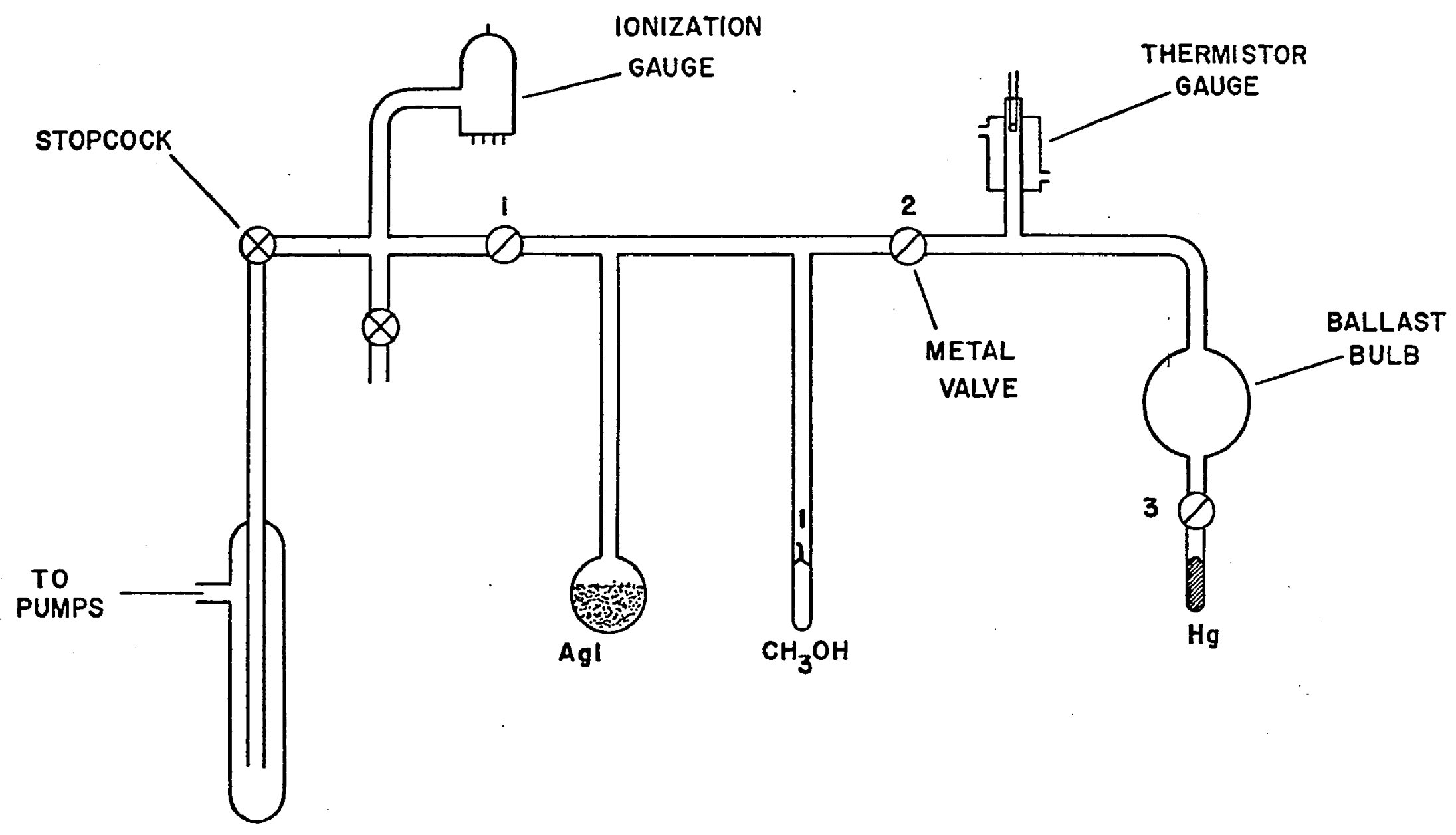

FIGURE 3. SYSTEM FOR DETERMINING THE EFFECT OF MERCURY VAPOR ON THE ADSORPTION OF METHANOL ON SILVER IODIDE 
was taken as a measure of the system pressure. The characteristics of a similar thermistor manometer were reported by Rosenberg (1955), for example. A complete cali- : bration curve for the thermistor was not needed but it was established that the sensitivity was approximately $10 \mathrm{mv} /$ micron in the pressure range of interest. The silver iodide sample was identical to that used in the sintering study by Corrin and Storm (1963). Approximately $0.5 \mathrm{~cm}^{3}$ at S.T.P. of methanol vapor was sealed in a bulb fitted with a break seal for the source of methanol in the system. Valves 1, 2 and 3 in the adsorption system were type 1197 bellows valves fitted with $\frac{1}{4}$-inch Swagelok connections by the manufacturer, Hoke, Incorporated. Teflon ferrules were used in the Swagelok connections to join the valves to selected lengths of $6 \mathrm{~mm}$ Pyrex tubing. The valves were rigidly secured to the grid supporting the system. The closed tube fitted to valve number 3 contained a few grams of mercury. The system was at ambient temperature.

Procedure

The purpose of the experiment was to learn if mercury vapor would displace adsorbed methanol from the silver 
iodide surface. The experiment was carried out as follows: The system was thoroughly outgassed until the pressure held at $2 \times 10^{-6} \mathrm{~mm}$. Valve number 3 was closed. Valve number 1 was closed. The break seal on the methanol bulb was crushed allowing the gas to enter the system. After several hours, valve number 2 was closed and valve number 3 was opened. The recorder trace was then started and the value of the off-balance voltage noted. Valve number 2 was opened and a period of eight hours allowed to elapse. The recorder trace showed no variation with time except for the initial dip due to the mercury vapor expansion and equilibration.

Since the amount of methanol in the system was sufficient to cover only about $10 \%$ of the silver iodide surface, presumably the higher energy sites, adsorption of mercury vapor would necessarily cause displacement of adsorbed methanol and hence produce an increase in pressure. Since no such pressure rise was observed, it was concluded that the presence of mercury vapor caused no measurable effect on the adsorption of methanol vapor on silver iodide. 


\section{Adsorption of Methanol Vapor on Silver Iodide}

Two separate systems were constructed to obtain the methanol adsorption data. The low pressure system employing a McLeod gauge as the primary pressure measuring instrument was used for pressure below five millimeters of mercury. Pressure measurements above five millimeters were made with the high pressure system by means of a wide-bore mercury manometer.

Materials

The silver iodide was obtained from a lot prepared by Ben Cooley and J. A. Nelson. The lot was prepared on July 6, 1965, by the method used for the preparation of $\mathrm{AgI}$ (II) described earlier in this work. The silver iodide was stored in a low-actinic Pyrex flask which was kept in a blackened vacuum desiccator. After each opening, the desiccator was promptly evacuated through a trap cooled to liquid nitrogen temperature. Special adsorption cells were constructed to prevent exposure of the silver iodide to the water vapor resulting from the hydrogen-oxygen torch flame used to seal the adsorption cells to the system. The B.E.T. surface area 
of the silver iodide was $1.14 \mathrm{~m}^{2} / \mathrm{g}$ at the time of the low pressure measurements. Three and one-half months later, at the time of the high pressure measurements, the B.E.T. surface area of the silver iodide was found to have decreased to $0.84 \mathrm{~m}^{2} / \mathrm{g}$.

Mercury used in the adsorption systems was obtained as reagent grade mercury and further purified by nitric acid and water washings and subsequent vacuum distillation. The methanol was obtained as Ma11inckrodt Anhydrous Methanol (Acetone free) for which the manufacturer specified the material to be greater than $99.5 \% \mathrm{CH}_{3} \mathrm{OH}$ and less than $0.05 \% \mathrm{H}_{2} \mathrm{O}$. This material was refluxed over magnesium turnings in a closed system fitted with a mercury blow-off tube for hydrogen venting. Teflon vacuum stop-. cocks were used exclusively in the methanol purification system. The first fraction of the reaction product was distilled into a receiving bulb and discarded. The next fraction was distilled into a second receiving bulb and retained. A portion of the second fraction was distilled into a bulb fitted with a break seal and a collapse seal. The bulb was then closed off from the rest of the system and cooled to liquid nitrogen temperature. The bulb was 
removed from the purification system by torching the collapse seal and subsequently sealed to the adsorption system. The purified methanol was then thoroughly degassed by repeatedly cooling the methanol bulb to liquid nitrogen temperature and pumping while the bulb warmed to room temperature.

The vapor pressure of the methanol was measured at three temperatures and found to differ by no more than $0.4 \%$ from the values given by the equation of Mlinde1 (1913). Approximately the same fit was obtained using the equation given in Lange (1961). Pressures were measured to $\pm 0.02 \mathrm{~mm}$ by means of the wide-bore manometer in the high pressure system. Temperatures were measured to $\pm 0.005^{\circ} \mathrm{C}$ by means of Philadelphia differential thermometers calibrated with a platinum resistance thermometer. The methanol was considered sufficiently pure for this investigation.

Methanol P-V-T data obtained from successive compressions in the McLeod gauge on the low pressure system were used to check the applicability of the perfect gas equation. The measurements were made at $26.3^{\circ} \mathrm{C}$ at ap- proximately $90 \%$ of the saturation pressure of methanol. 
For each compression, the number of moles of methanol was calculated using the perfect gas equation and compared to the value obtained using the virial equation discussed by Beattie (1949). A maximum deviation of $0.25 \%$ was observed and the deviations showed no trend with increasing pressure. It was concluded that the perfect gas approximation was applicable.

Temperature Measurement and Contro1

Adsorption measurements were carried out at $30.02^{\circ}, 19.79^{\circ}$ and $9.77^{\circ} \mathrm{C}$. Three Philadelphia differential thermometers were used for temperature measurements, one for each of the three isotherm temperatures. Each of the thermometers was calibrated against platinum resistance thermometer number 17 manufactured by Rosemount Engineering Co. The resistance thermometer was calibrated by the National Bureau of Standards in test number $3.1 / \mathrm{G} 33289$. The thermometer was used in conjunction with a Leeds and Northrop Mueller Bridge and a Keithley microvoltmeter as a nul1 detector. A constant current of 2 ma was maintained through the thermometer resistance element during measurements. The response of the differential 
thermometers was found to be linear. A working equation was obtained for each of the differential thermometers from least square analyses of the calibration data. The uncertainty in reading the differential thermometers was essentially the same as that for the resistance thermometer, e.g., 0.005 degree. t?

The temperature of the adsorbent cell was regulated with a thermostated water bath. A Sargent Thermonitor was used as a circulating pump and heater. The unit was equipped with a thermistor temperature transducer which was found sufficient for temperature control of \pm 0.01 degree. For temperatures below room temperature a refrigeration unit was used to pump coolant through coils in the water bath.

The Low Pressure System

The vacuum system shown in Figure 4 was used for adsorption measurements in the lower pressure region. The pumping system for both the low pressure system and the high pressure system was identical to that used in. the water adsorption system. The McLeod gauge was used 


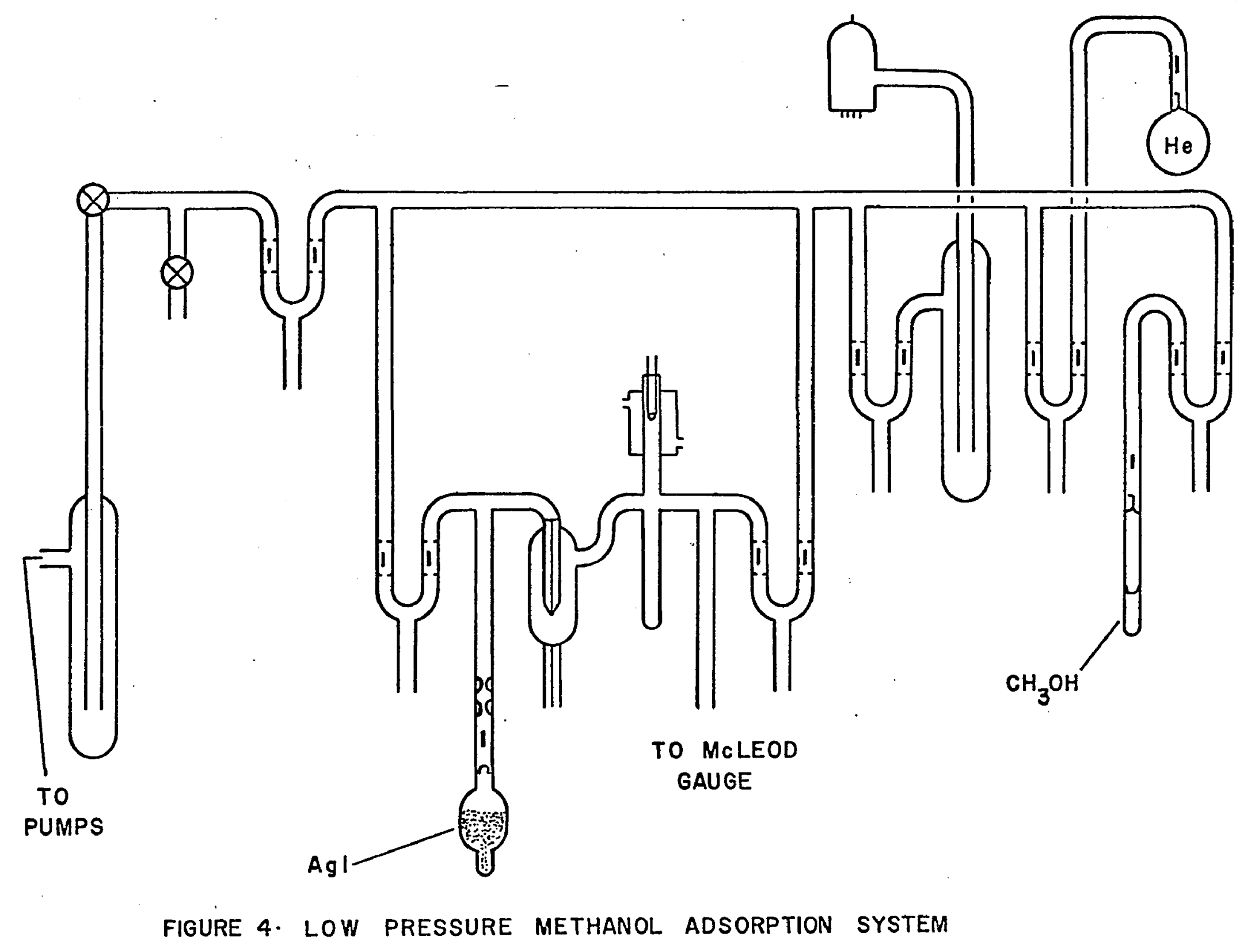


to measure the equilibrium pressure of methanol and as a doser. Precision-bore tubing of 3/16-inch inside diameter was used in the arms of the McLeod gauge. The total vo1ume of the gauge and the volume of the closed arm were determined by weighing the amount of mercury required to fill the volumes. Triplicate determinations for the smal1er volume agreed within $0.1 \%$ whereas agreement for the larger volume was within $0.02 \%$. The volumes were corrected for the effects of the mercury meniscus according to the method given by Partington (1949). The corrected volume of the closed arm was found by this method to be $3.414 \pm 0.003 \mathrm{~cm}^{3}$ and the total volume was found to be $34.323 \pm 0.006 \mathrm{~cm}^{3}$. For pressure measurements the difference in height between the columns of mercury was measured with a Gaertner telemicroscope fitted with an M202 filar eyepiece. A Gaertner M1018 precision divided stainless steel scale was rigidly mounted directly behind the arms of the McLeod gauge. The smallest division on the scale was $1 \mathrm{~mm}$. The filar eyepiece provided approximately one hundred divisions between two adjacent millimeter divisions inscribed on the scale. Using this 
arrangement, heights could be estimated to the nearest $0.002 \mathrm{~mm}$. Due to the fact that the scale was in very near1y the same plane as the arms of the McLeod gauge, precise leveling of the telescope was unnecessary.

As a check on the constancy of the McLeod gauge, a series of compressions was made on a volume of helium. The PV products showed a dependence upon the pressure. The cause of this trend was attributed to the value of the radius of the precision-bore tubing used in the working equation of the McLeod gauge. The value used in the above calculations was that supplied by the manufacturer, 0.09375 inch. By assuming that the PV products must be independent of pressure (the perfect gas approximation), an equation was derived for the experimental determination of the radius of the precision-bore tubing.

$$
\mathrm{PV}=\mathrm{k}
$$

where $P$ is the pressure, $V$ is the volume of the gas in the closed arm and $\mathrm{k}$ is a constant.

$$
\begin{aligned}
& \mathrm{P}=\mathrm{h}_{2}-\mathrm{h}_{1} \\
& \mathrm{~V}=3.414 \mathrm{~cm}^{3}-\pi \mathrm{r}^{2}\left(\mathrm{~h}_{1}-\mathrm{h}_{\mathrm{o}}\right)
\end{aligned}
$$


where

$\mathrm{h}_{1}=$ height of mercury column in closed arm in $\mathrm{cm}$

$\mathrm{h}_{2}=$ height of mercury column in open arm in $\mathrm{cm}$

$h_{0}=$ height of reference mark on closed arm in $\mathrm{cm}$

$r$ = radius of capillary in $\mathrm{cm}$

Substitution of the values of $P$ and $V$ into equation (21) yields

$$
h_{1}-h_{0}=\left(3.414 / \pi r^{2}\right)-\left(k / \pi r^{2}\right) /\left(h_{2}-h_{1}\right)
$$

By plotting the quantity $\left(h_{1}-h_{0}\right)$ as a function of $1 /\left(h_{2}-h_{1}\right)$ a straight 1 ine of intercept $3.414 / \pi r^{2}$ was obtained. The value of $\pi r^{2}$ obtained by least square analysis of the helium compression data was $0.17726 \mathrm{~cm}^{2}$. The corresponding value of $r$ was found to be 0.09353 inch which was within the manufacturer's accepted tolerance for the precision-bore tubing. Use of the experimentally determined radius produced no trends in subsequent compression data. The working equation for calculation of the pressure in the adsorption system was

$$
P(m)=\left(h_{2}-h_{1}\right)\left(3.414-0.017726\left(h_{1}-h_{0}\right)\right) / 34.323
$$

where the heights are now expressed in millimeters.

The thermistor gauge on the low pressure system was identical to that described earlier. The rate of 
attainment of equilibrium and the rate of degassing were monitored with the thermistor gauge. The closed tube below the thermistor gauge was used as a condensing bulb for zeroing the gauge.

The adsorption cell consisted of a bulb fitted at one end with a hemispherical break seal and a length of $12 \mathrm{~mm}$ tubing at the open end. The cell was filled with 10.72 grams of silver iodide through a funnel inserted in the open end of the cell. The silver iodide flowed freely into the cell. The cell was then promptly sealed off by torching the $12 \mathrm{~mm}$ tubing about midway between the bulb and the end of the tubing. These precautions were taken to avoid exposure of the silver iodide to water vapor. The cell was then sealed to the adsorption system, the break seal crushed and the system pumped out. Dead-space volumes were obtained by expanding doses of helium into the system and measuring the resulting pressure. Duplicate determinations for each volume agreed within $0.1 \%$. The low pressure system constants are given in Table 3 . 
TABLE 3

Low Pressure System Constants

\begin{tabular}{|c|c|c|}
\hline \multicolumn{3}{|c|}{ Blank Adsorption } \\
\hline$E(O C)$ & $V_{\text {tota } 1}\left(\mathrm{~cm}^{3}\right)$ & $V_{\text {sample-side }}\left(\mathrm{cm}^{3}\right)$ \\
\hline 9.77 & 107.49 & 27.63 \\
\hline 19.79 & 107.12 & 27.09 \\
\hline \multirow[t]{2}{*}{30.02} & 106.67 & 26.50 \\
\hline & Total Ad & . \\
\hline$t\left({ }^{\circ} \mathrm{C}\right)$ & $V_{\text {total }}\left(\mathrm{cm}^{3}\right)$ & $V_{\text {sample-side }}\left(\mathrm{cm}^{3}\right)$ \\
\hline 9.77 & 109.11 & 31.11 \\
\hline 19.79 & 108.61 & 30.57 \\
\hline 30.02 & 108.25 & 30.04 \\
\hline
\end{tabular}

Weight of $\mathrm{AgI}=10.72 \mathrm{~g}$

Specific surface area of $\mathrm{AgI}=1.14 \mathrm{~m}^{2} / \mathrm{g}$ 
The low-volume mercury cutoff between the sample bulb and the McLeod gauge prevented compression of gas in the adsorption bulb during a pressure measurement. .

Each of the mercury float valves was thoroughly outgassed by heating and repeatedly raising and lowering the mercury until no significant change in pressure was observed as measured with the Veeco ionization gauge set on the $10^{-6} \mathrm{~mm}$ scale. The entire system was outgassed for a period of a week until the pressure remained at $2 \times 10^{-7} \mathrm{~mm}$ with the pumps closed off.

Low Pressure Adsorption

The volumetric method described earlier was used for obtaining the low pressure methanol adsorption data. Doses of methanol were metered out with the McLeod gauge which was also used for measuring the equilibrium pressure in the system. The maximum dose which could be measured was limited by the condensation in the doser. The maximum dose was $2.2 \times 10^{-5}$ moles of methano1. Duplicate compressions agreed within $0.1 \%$. The temperature variation method was used so that a single sample of silver iodide could be used to obtain the low pressure adsorption data 
for all three temperatures. This technic involved resetting the temperature of the thermostat after each dose, being especially careful to make sure that the number of moles in the next dose was sufficient to provide greater surface coverage. Some desorption was encountered in changing temperatures but this appeared to be reversible. Blank adsorption isotherms were measured to correct for the amount of methanol taken up by the adsorption apparatus. The blank adsorption data are given in Table 4 and the isotherms are shown in Figure 5. Maxima were observed in all three blank adsorption isotherms. The maxima are interpreted in terms of a decrease in the effective surface area of the adsorption apparatus. Smooth curves were drawn through the blank adsorption isotherm points and the gross adsorption was then corrected, point by point, for the blank adsorption. The corrected adsorption data are given in Table 5. The low pressure adsorption of methanol on silver iodide is shown in Figure 6 as the amount adsorbed per unit area as a function of pressure. 
TABLE 4

Blank Low Pressure Adsorption Data

\begin{tabular}{|c|c|c|c|}
\hline Dose & $V_{\text {ads }}\left(\mathrm{cm}^{3}\right)$ & $P(\mathrm{~mm})$ & $t\left({ }^{\circ} \mathrm{C}\right)$ \\
\hline 1 & 0.008278 & 0.46284 & 9.77 \\
\hline 2 & 0.010925 & 1.03529 & 9.77 \\
\hline 3 & 0.014708 & 1.69847 & 9.77 \\
\hline 4 & 0.018483 & 2.54942 & 9.77 \\
\hline 5 & 0.020702 & 3.56313 & 9.77 \\
\hline 6 & 0.019776 & 4.58015 & 9.77 \\
\hline 1 & 0.004481 & 0.50933 & 30.02 \\
\hline 2 & 0.006507 & 0.61152 & 19.79 \\
\hline 3 & 0.007935 & 1.30418 & 30.02 \\
\hline 4 & 0.009548 & 1.68432 & 19.79 \\
\hline 5 & 0.010586 & 2.44149 & 30.02 \\
\hline 6 & 0.011608 & 2.82359 & 19.79 \\
\hline 7 & 0.010665 & 3.83085 & 30.02 \\
\hline 8 & 0.009158 & 3.95812 & 19.79 \\
\hline 9 & 0.007536 & 4.69394 & 19.79 \\
\hline 10 & 0.006769 & 4.82632 & 30.02 \\
\hline
\end{tabular}




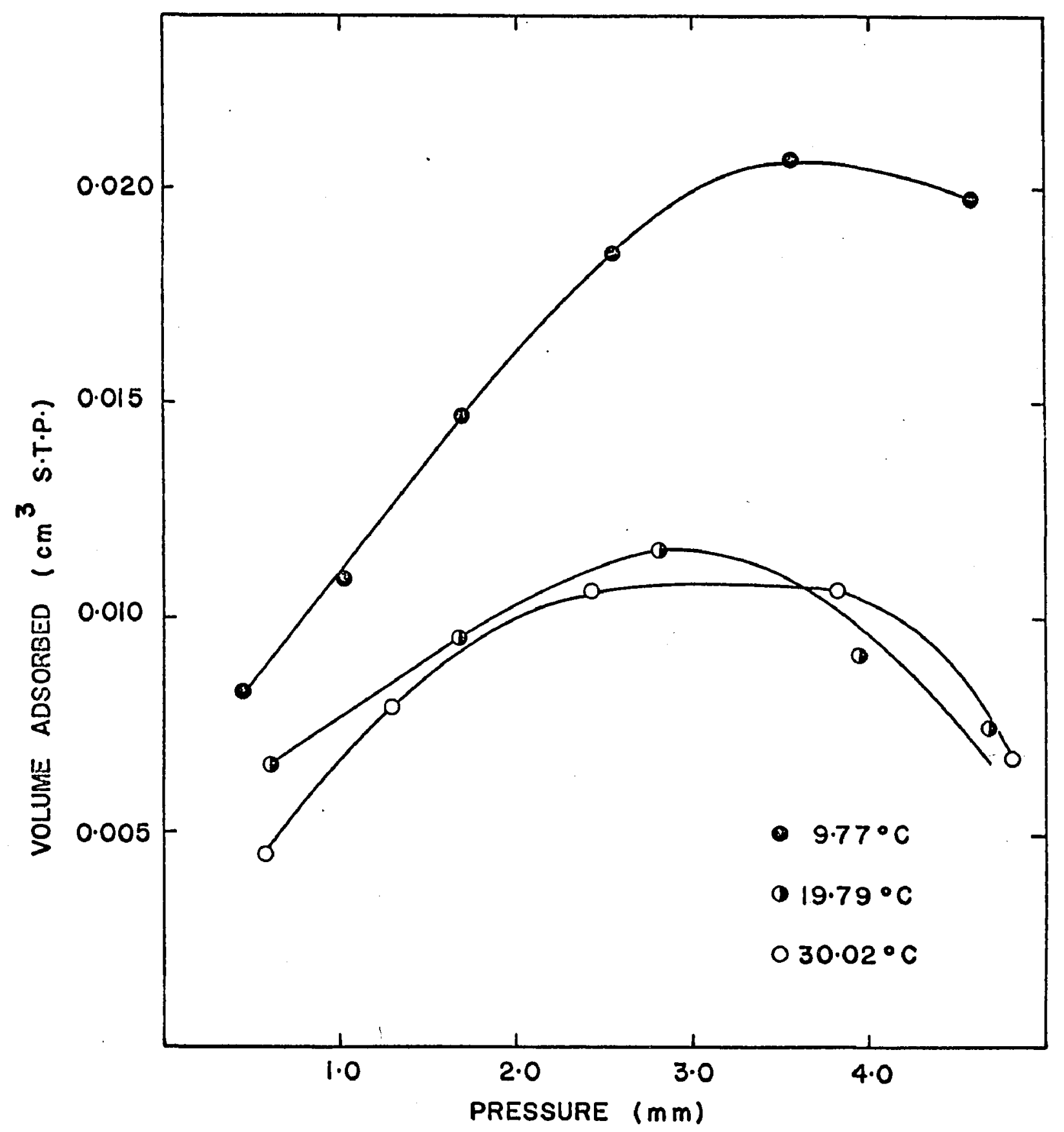

FIGURE 5. LOW PRESSURE BLANK METHANOL ADSORPTION ISOTHERMS 
TABLE 5

Low Pressure Adsorption Data

\begin{tabular}{ccccccr}
\hline \hline Dose & $\mathrm{V}_{\text {ads }}\left(\mathrm{cm}^{3}\right)$ & $\begin{array}{c}\mathrm{V}_{\text {ads }}\left(\mathrm{cm}^{3}\right) \\
(\mathrm{bIank})\end{array}$ & $\begin{array}{c}\mathrm{V}_{\mathrm{ads}}(\mathrm{cm}) \\
(\mathrm{net})\end{array}$ & $\begin{array}{c}\mathrm{V}_{\mathrm{ads}} / \mathrm{A}\left(\mathrm{cm}^{3} / \mathrm{m}^{2}\right) \\
(\mathrm{net})\end{array}$ & $\mathrm{P}(\mathrm{mm})$ & $\mathrm{t}\left({ }^{\circ} \mathrm{C}\right)$ \\
\hline 1 & 0.062748 & 0.00315 & 0.05960 & 0.00488 & 0.24405 & 30.02 \\
2 & 0.115692 & 0.00564 & 0.11005 & 0.00901 & 0.33802 & 19.79 \\
3 & 0.191754 & 0.00779 & 0.18396 & 0.01505 & 0.39538 & 9.77 \\
4 & 0.183615 & 0.00759 & 0.17603 & 0.01441 & 1.22547 & 30.02 \\
5 & 0.218205 & 0.00724 & 0.21097 & 0.01726 & 0.86568 & 19.79 \\
6 & 0.261439 & 0.00894 & 0.25250 & 0.02066 & 0.61461 & 9.77 \\
7 & 0.266776 & 0.01045 & 0.25633 & 0.02098 & 2.26205 & 30.02 \\
8 & 0.306801 & 0.00939 & 0.29741 & 0.02434 & 1.60659 & 19.79 \\
9 & 0.364306 & 0.01215 & 0.35216 & 0.02882 & 1.22143 & 9.77 \\
10 & 0.359061 & 0.01009 & 0.34897 & 0.02856 & 4.15889 & 30.02 \\
\hline
\end{tabular}


TABLE 5--Continued

\begin{tabular}{lllcccr}
\hline \hline Dose & $\mathrm{V}_{\text {ads }}\left(\mathrm{cm}^{3}\right)$ & $\begin{array}{c}\mathrm{V}_{\text {ads }}\left(\mathrm{cm}^{3}\right) \\
\text { (blank) }\end{array}$ & $\begin{array}{c}\mathrm{V}_{\text {ads }}\left(\mathrm{cm}^{3}\right) \\
\text { (net) }\end{array}$ & $\begin{array}{c}\mathrm{V}_{\mathrm{ads}} / \mathrm{A}\left(\mathrm{cm}^{3} / \mathrm{m}^{2}\right) \\
(\mathrm{net})\end{array}$ & $\mathrm{P}(\mathrm{mm})$ & $t\left({ }^{\circ} \mathrm{C}\right)$ \\
11 & 0.406267 & 0.01151 & 0.39477 & 0.03231 & 2.97856 & 19.79 \\
12 & 0.489988 & 0.01807 & 0.47192 & 0.03862 & 2.45246 & 9.77 \\
13 & 0.397653 & 0.00547 & 0.39218 & 0.03209 & 4.99358 & 30.02 \\
14 & 0.482399 & 0.00835 & 0.47405 & 0.03879 & 4.40508 & 19.79 \\
15 & 0.605947 & 0.02028 & 0.58567 & 0.04793 & 4.09467 & 9.77 \\
16 & 0.644151 & 0.01909 & 0.62506 & 0.05115 & 4.64259 & 9.77 \\
\hline
\end{tabular}




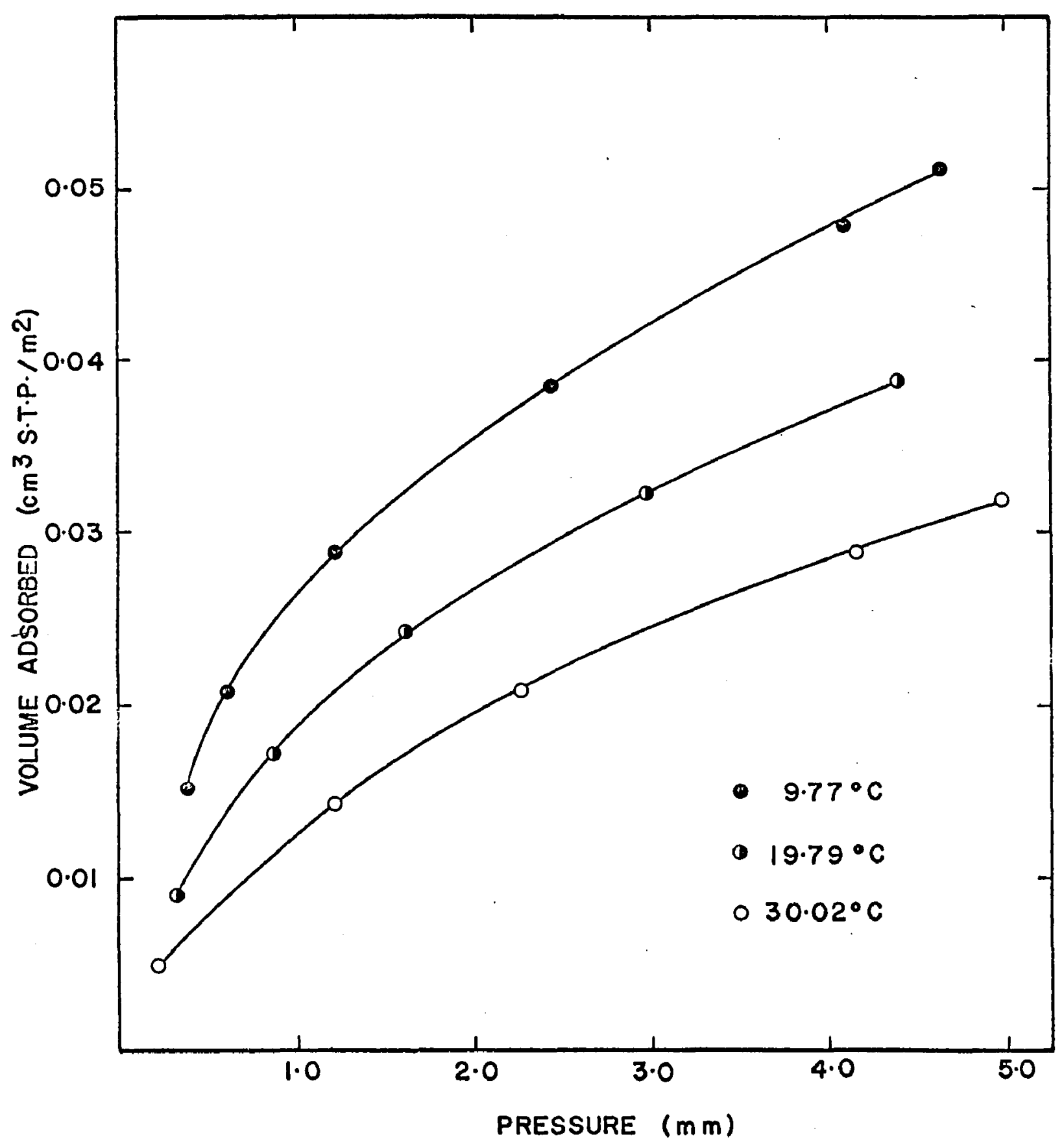

FIGURE 6. LOW PRESSURE METHANOL ADSORPTION ISOTHERMS 
The High Pressure System

To carry out the adsorption measurements above five millimeters of pressure, the vacuum system shown in Figure 7 was constructed. The pumping system was identical to that described earlier. As in the low pressure system, mercury float valves were used in those parts of the adsorption system in which the actual measurements were taken. It was found convenient, however, to use ordinary vacuum stopcocks where interaction of methanol with stopcock lubricant would not lead to erroneous adsorption measurements. The use of these stopcocks resulted in a somewhat higher minimum outgassing pressure, e.g., $2 \times 10^{-6} \mathrm{~mm}$. The major differences in the high pressure system are in the devices used for dosing and pressure measurement. A null manometer was used to determine the pressure in the system and that portion of the system from the nul1 manometer to the low-volume cutoff was used as the dosing volume. The nul1 manometer consisted of a mercury manometer which was joined to the adsorption system through a capillary tube. The other arm of the manometer was connected to a wide-bore mercury manometer constructed of 3/4-inch precision-bore tubing to equalize mercury depression 


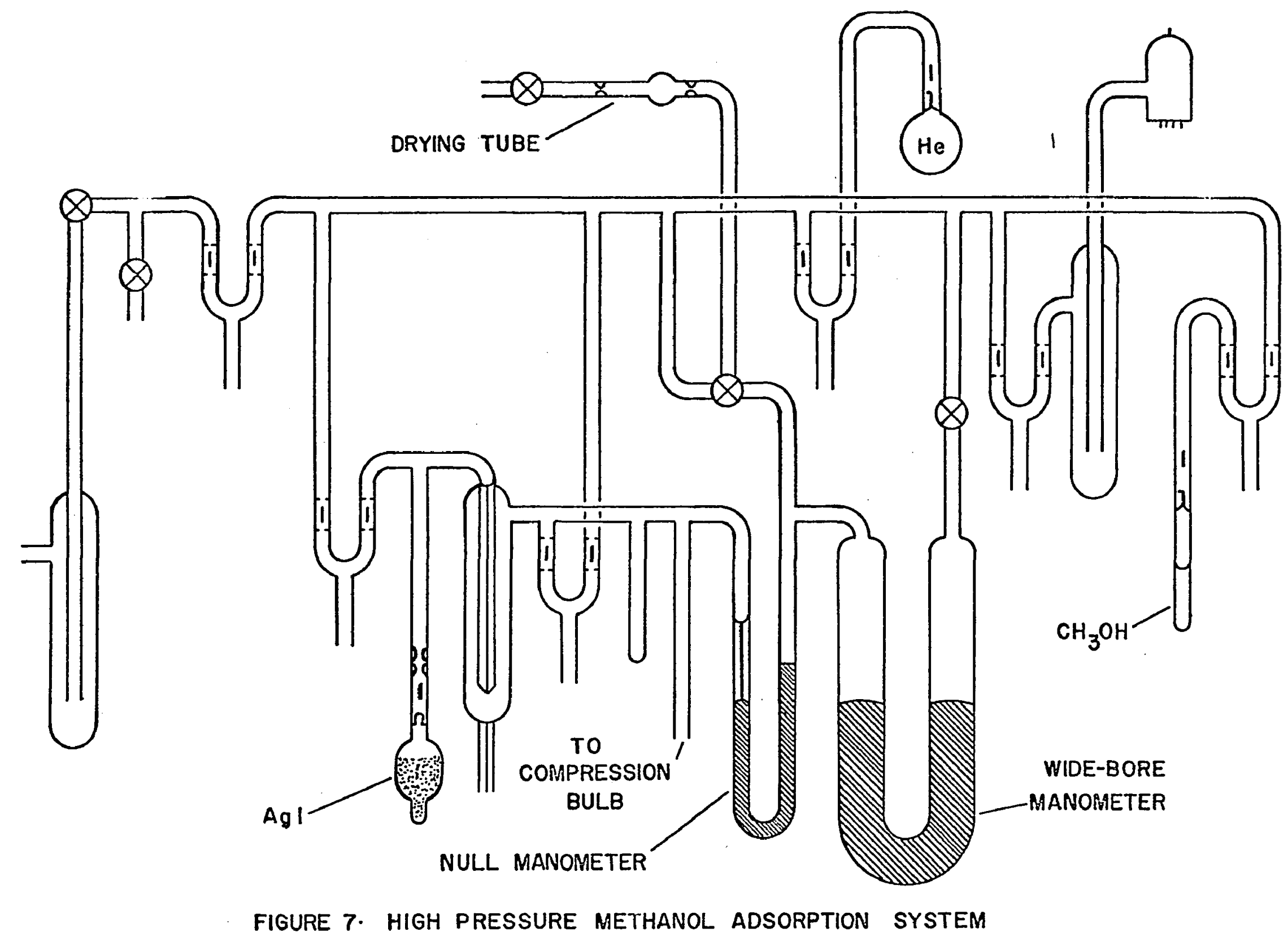


effects. The volume between the right arm of the nu11 manometer and the left arm of the wide-bore manometer was fitted with a three-way vacuum stopcock which allowed this space to be evacuated or to be filled with air from the drying tube. When the pressure on both arms of the null manometer was made equal by opening both arms to the pumps, a mark was inscribed on the capillary tube on the left arm corresponding to the height of the mercury in the left arm. Determination of the pressure in the adsorption system was accomplished by admitting sufficient dry air to the volume between the two manometers to restore the mercury in the capillary of the left arm of the null manometer to the null position. With the right arm of the wide-bore manometer under vacuum, the pressure of the air in the space between the manometers was equal to the pressure of the gas in the adsorption system. This pressure was determined by using a cathetometer which could be read to $0.01 \mathrm{~mm}$ to measure the heights of the mercury columns in the wide-bore manometer. The use of the capillary tube in the null manometer permitted the volume of the adsorption system to be kept constant for all adsorption measurements. The adsorption system was fitted with a calibrated 
compression bulb which permitted the volume of the adsorption system to be changed by a known increment for determination of the dead-space volumes of the system. The compression bulb was calibrated by weighing the amount of water required to fill the volume. Triplicate determinations agreed within $0.03 \%$.

An adsorption cell similar to that used in the low pressure measurements was filled with 10.22 grams of silver iodide and sealed to the system. The break seal was crushed and the system pumped out.

The dosing volume was determined as the volume between the mark on the capillary on the null manometer and a mark on the low-volume cutoff. A dose of helium was trapped in this volume and the pressure measured. The dose was then compressed by filling the compression bulb with mercury from its reservoir and the resulting pressure determined. The dosing volume was given by

$$
\mathrm{V}_{\text {dosing }}=\mathrm{P}_{2} \times \mathrm{V}_{\text {compr }} /\left(\mathrm{P}_{2}-\mathrm{P}_{1}\right)
$$

where $\mathrm{V}_{\text {compr }}$ is the previously determined volume of the compression bulb. Total dead-space volumes were determined similarly. The sample-side dead-space volumes were determined by expansion of helium from the sample-side 
volume into the known total volume. Dupíicate volume determinations agreed within $0.1 \%$. The high pressure system constants are given in Table 6.

High Pressure Adsorption

The volumetric method described earlier was also used for obtaining the high pressure methanol adsorption data. Doses of methanol were metered out from the dosing volume in the adsorption system. Pressures were measured using the null manometer device with the cathetometer. Since the constancy of compression ratios could not be used as a check on the pressure measurements, duplicate pressure measurements were taken. After the first rough measurement was made, the mercury in the nu11 manometer was displaced from the equilibrium position by changing the pressure of the air in the space between the manometers. Equilibrium was then re-established and the final pressure measurement made. This process was repeated until agreement within $0.01 \mathrm{~mm}$ was obtained. Generally, no more than two displacements were required. After each dose was applied, a period of at least eight hours was 
TABLE 6

High Pressure System Constants

\begin{tabular}{rcc}
\hline$t\left({ }^{\circ} \mathrm{C}\right)$ & $v_{\text {total }}\left(\mathrm{cm}^{3}\right)$ & $v_{\text {sample-side }}\left(\mathrm{cm}^{3}\right)$ \\
9.77 & 128.89 & 29.89 \\
19.79 & 128.31 & 29.26 \\
30.02 & 127.77 & 28.62 \\
\hline
\end{tabular}

Compression Bulb Volume $=36.99 \mathrm{~cm}^{3}$

Dosing Volume $=93.37 \mathrm{~cm}^{3}$

Weight of Silver Iodide $=10.22 \mathrm{~g}$

Specific surface area of $\mathrm{AgI}=0.84 \mathrm{~m}^{2} / \mathrm{g}$ 
allowed to pass for equilibrium to be established before the pressure measurement was made.

The temperature variation method was also used in collecting the high pressure data. Correction for the amount of gas taken up by the adsorption apparatus was not necessary since the low pressure blank adsorption data showed that the correction would be more than two orders of magnitude less than the gross adsorption for this pressure range.

The high pressure adsorption data are given in Table 7 and the adsorption isotherms are shown in Figure 8 . For the adsorption at $30.02^{\circ}$ and $19.79^{\circ} \mathrm{C}$ the amount of methanol adsorbed per unit area was found to be linearly dependent upon the pressure. By means of least squares analyses, the best straight lines were obtained for the two isotherms. The two isotherm equations are as follows:

$$
\begin{aligned}
& \mathrm{V}_{\text {ads }}\left(30.02^{\circ} \mathrm{C}\right) / \mathrm{A}=0.0021512 \mathrm{p}+0.0145213 \\
& \mathrm{~V}_{\text {ads }}\left(19.79^{\circ} \mathrm{C}\right) / \mathrm{A}=0.0038625 \mathrm{p}+0.0134084
\end{aligned}
$$

The $9.77^{\circ} \mathrm{C}$ isotherm was found to be non-linear and a smooth curve was drawn through the isotherm points. The high pressure isotherms did not quite link up with the low pressure isotherms, the high pressure adsorption being too low 
TABLE 7

High Pressure Adsorption Data

\begin{tabular}{|c|c|c|c|c|}
\hline Dose & $V_{\text {ads }}\left(\mathrm{cm}^{3}\right)$ & $V_{\text {ads }} / \mathrm{A}\left(\mathrm{cm}^{3} / \mathrm{m}^{2}\right)$ & $P(\mathrm{~mm})$ & $t\left({ }^{\circ} \mathrm{C}\right)$ \\
\hline 1 & 0.23120 & 0.026946 & 7.84 & 30.02 \\
\hline 2 & 0.40858 & 0.047620 & 8.53 & 19.79 \\
\hline 3 & 0.59776 & 0.069668 & 9.97 & 9.77 \\
\hline 4 & 0.48450 & 0.056468 & 18.98 & 30.02 \\
\hline 5 & 0.86281 & 0.100560 & 23.92 & 19.79 \\
\hline 6 & 1.81017 & 0.210975 & 24.98 & 9.77 \\
\hline 7 & 0.97651 & 0.113812 & 46.18 & 30.02 \\
\hline 8 & 1.14858 & 0.133867 & 30.02 & 19.79 \\
\hline 9 & 2.07108 & 0.241384 & 29.55 & 9.77 \\
\hline 10 & 1.41139 & 0.164497 & 68.77 & 30.02 \\
\hline 11 & 1.57429 & 0.183483 & 44.56 & 19.79 \\
\hline 12 & 2.86872 & 0.334349 & 45.79 & 9.77 \\
\hline 13 & 1.84263 & 0.214758 & 93.14 & 30.02 \\
\hline 14 & 2.27796 & 0.265496 & 65.45 & 19.79 \\
\hline 15 & 3.36342 & 0.392006 & 48.83 & 9.77 \\
\hline 16 & 2.10604 & 0.245459 & 107.93 & 30.02 \\
\hline 17 & 2.78604 & 0.324713 & 80.44 & 19.79 \\
\hline
\end{tabular}




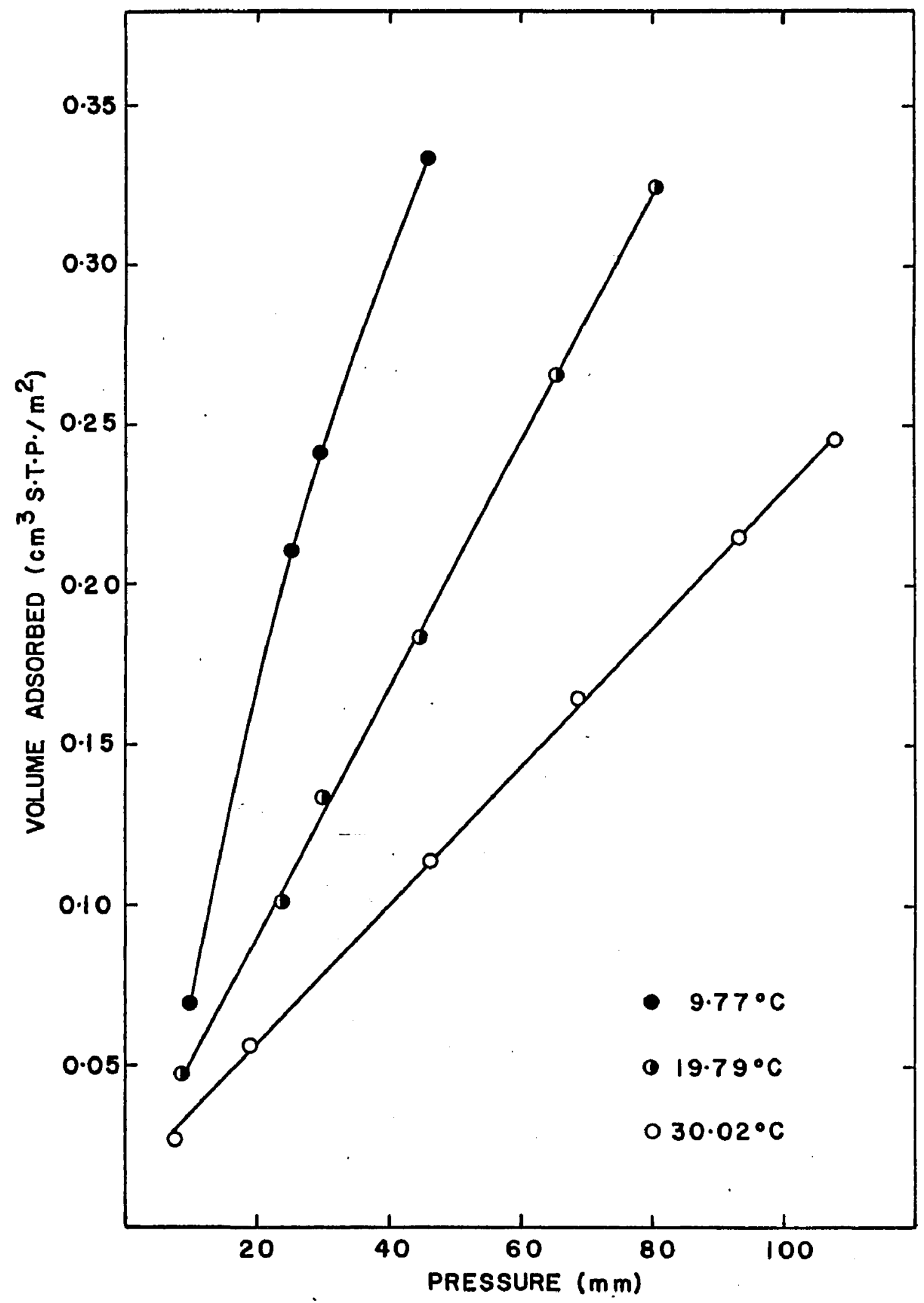

FIGURE 8. HIGH PRESSURE METHANOL ADSORPTION ISOTHERMS 
in all three cases. The deviation was greatest for the $30.02^{\circ} \mathrm{C}$ isotherms and least for the $9.77^{\circ} \mathrm{C}$ isotherms. This observation is consistent with the assumption that the higher energy sites are predominant in both the sintering process and in the higher temperature adsorption process.

\section{Calculations}

Isosteric heats of adsorption were calculated from the adsorption isotherm data by evaluating the slopes of the adsorption isosteres. From equation (14) it is apparent that the quantity $\mathrm{q}_{\text {st }}$ may be obtained from the slope of the linear relation between $\log \mathrm{p}$ and $1 / \mathrm{T}$.

The low pressure adsorption data in Table 5 were plotted on a large sheet of graph paper. For a given volume adsorbed per square meter, the values of the pressures at each of the adsorption temperatures were obtained from the graph. For each coverage, a plot of $\log p$ against $1 / T$ was made. These plots are termed adsorption isosteres. Typical adsorption isosteres for both low and high pressure adsorption are shown in Figure 9. Since the adsorption isosteres were linear, the slopes were calculated by least squares analyses. The low pressure heat 


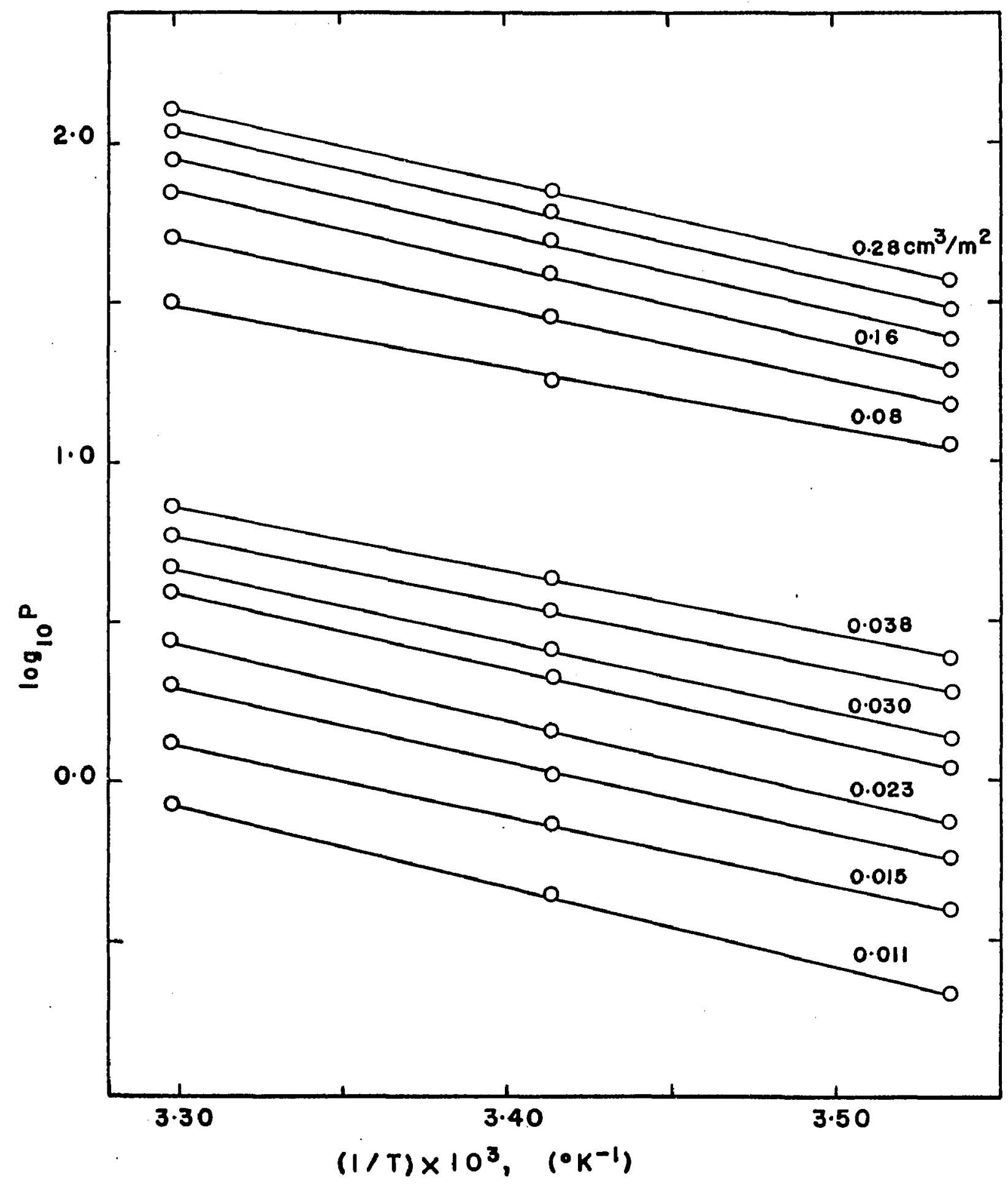

FIGURE 9. ADSORPTION ISOSTERES 
of adsorption data are summarized in Table 8 and the low pressure heat of adsorption is presented as a function of volume adsorbed per square meter in Figure 10.

A procedure similar to that described in the preceding paragraph was employed in calculating the heat of adsorption in the higher pressure range except that only the adsorption data at $9.77^{\circ} \mathrm{C}$ from Table 7 required graphing. For the two higher temperatures, the pressures at given coverages were calculated from equations (24) and (25). Least square analyses were applied to these data which are summarized in Table 9. The heats of adsorption in the higher pressure range are shown in Figure 11.

The differential entropies of adsorption were calculated from a modified form of equation (15). Differential entropies of adsorption were calculated with reference to the liquid adsorbate using

$$
\bar{S}_{S}-S_{L}^{\prime}=-\left(q_{S t} / T\right)+(U / T)-R \ln \left(P / P_{0}\right)
$$

where

$$
\begin{aligned}
& \bar{S}_{S}=\text { partial molar entropy of the adsorbed gas } \\
& S_{L}^{\prime}=\text { molar entropy of the liquid at the temperature } T
\end{aligned}
$$


$\mathrm{U}=$ molar heat of vaporization of the liquid

$\mathrm{R}=$ gas constant in $\mathrm{cal} / \mathrm{mole} / \mathrm{deg}$

$\mathrm{P}_{\mathrm{o}}=$ vapor pressure of liquid at $\mathrm{T}$

The central isotherm temperature of $19.79^{\circ} \mathrm{C}$ was chosen for the entropy calculation. From the equation given in Lange (1961) the vapor pressure of methanol at this temperature is $95.77 \mathrm{~mm}$. The data used for calculation of the differential entropies of adsorption are given in Table 10 and Table 11. The variation in the differential entropy with volume adsorbed per square meter is shown in Figure 12 and Figure 13. 
TABLE 8

Isosteric Heat of Adsorption

Low Pressure Data

$$
\mathrm{V}_{\text {ads }}(\mathrm{net}) / \mathrm{A}\left(\mathrm{cm}^{3} / \mathrm{m}^{2}\right) \quad \mathrm{q}_{\mathrm{st}}(\mathrm{kcal} / \mathrm{mole})
$$

$\begin{array}{ll}0.01053 & 11.493 \\ 0.01228 & 10.690 \\ 0.01404 & 10.148 \\ 0.01491 & 10.097 \\ 0.01579 & 10.010 \\ 0.01667 & 10.024 \\ 0.01754 & 10.048 \\ 0.01842 & 10.266 \\ 0.01930 & 10.455 \\ 0.02018 & 10.599 \\ 0.02105 & 10.771 \\ 0.02193 & 10.885 \\ 0.02281 & 10.925 \\ 0.02368 & 10.942 \\ 0.02456 & 10.937 \\ 0.02544 & 10.848\end{array}$


TABLE 8--Continued

\begin{tabular}{cc}
\hline $\mathrm{V}_{\mathrm{ads}}(\mathrm{net}) / \mathrm{A}\left(\mathrm{cm}^{3} / \mathrm{m}^{2}\right)$ & $\mathrm{q}_{\mathrm{st}}(\mathrm{kcal} / \mathrm{mole})$ \\
\hline 0.02632 & 10.759 \\
0.02719 & 10.658 \\
0.02807 & 10.539 \\
0.02895 & 10.414 \\
0.02982 & 10.280 \\
0.03070 & 10.162 \\
0.03158 & 10.043 \\
0.03400 & 9.606 \\
0.03600 & 9.344 \\
0.03800 & 9.110 \\
\hline
\end{tabular}




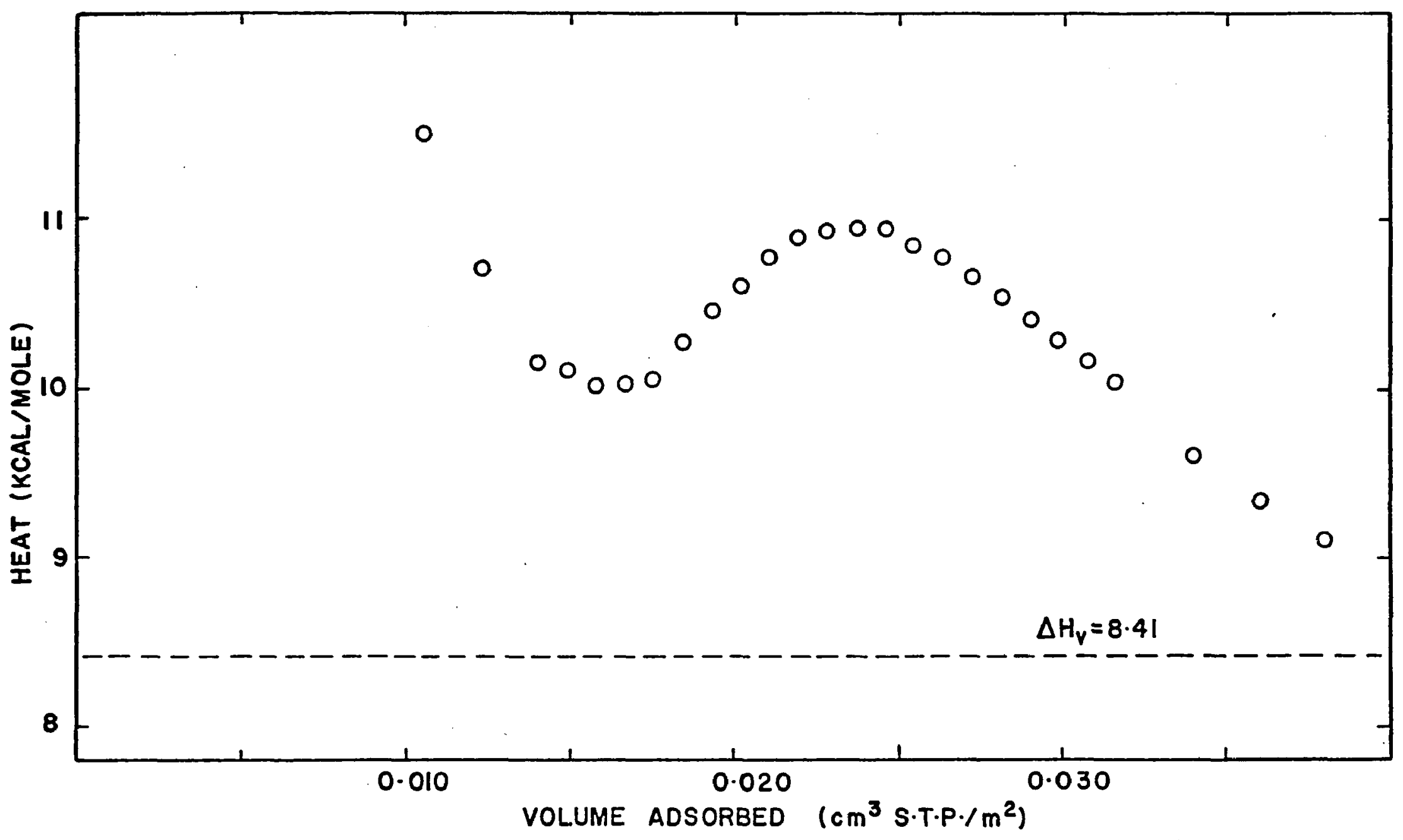

FIGURE 10- ISOSTERIC HEATS OF ADSORPTION, LOW PRESSURE DATA

บั 
TABLE 9

Isosteric Heat of Adsorption

High Pressure Data

\begin{tabular}{|c|c|}
\hline$V_{\text {ads }}($ net $) / A\left(\mathrm{~cm}^{3} / \mathrm{m}^{2}\right)$ & $\mathrm{q}_{\mathrm{st}}(\mathrm{kcal} / \mathrm{mole})$ \\
\hline 0.07 & 7.964 \\
\hline 0.08 & 8.485 \\
\hline 0.09 & 9.057 \\
\hline 0.10 & 9.418 \\
\hline 0.11 & 9.726 \\
\hline 0.12 & 10.031 \\
\hline 0.13 & 10.247 \\
\hline 0.14 & 10.409 \\
\hline 0.15 & 10.564 \\
\hline 0.16 & 10.728 \\
\hline 0.17 & 10.812 \\
\hline 0.18 & 10.860 \\
\hline 0.19 & 10.883 \\
\hline 0.20 & 10.927 \\
\hline 0.21 & 10.909 \\
\hline 0.22 & 10.912 \\
\hline
\end{tabular}


TABLE 9--Continued

\begin{tabular}{cc}
\hline \hline$V_{\text {ads }}($ net $) / \mathrm{A}\left(\mathrm{cm}^{3} / \mathrm{m}^{2}\right)$ & $\mathrm{q}_{\mathrm{st}}$ \\
\hline 0.23 & $(\mathrm{kcal} / \mathrm{mole})$ \\
0.24 & 10.862 \\
0.25 & 10.767 \\
0.28 & 10.668 \\
0.31 & 10.338 \\
\hline
\end{tabular}




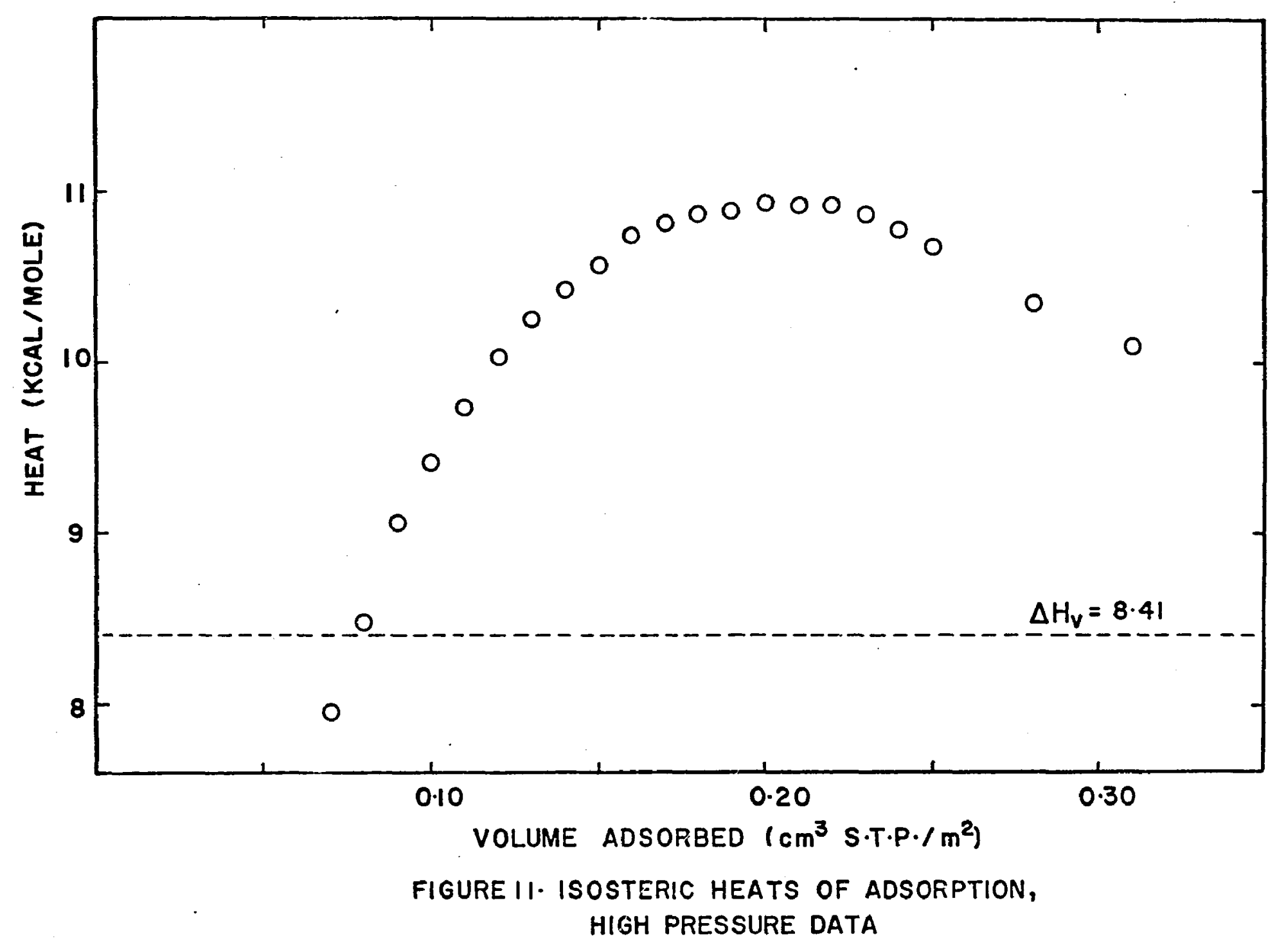


TABLE 10

Differential Entropy of Adsorption

Low Pressure Data

\begin{tabular}{ccccc}
\hline \hline $\begin{array}{c}\mathrm{V} / \mathrm{A} \\
\left(\mathrm{cm}^{3} / \mathrm{m}^{2}\right)\end{array}$ & $\begin{array}{c}\mathrm{q}_{\mathrm{st}} \\
(\mathrm{kcal} / \mathrm{mole})\end{array}$ & $\begin{array}{c}\mathrm{P} \\
(\mathrm{mm})\end{array}$ & $\log \mathrm{P}$ & $\begin{array}{c}\overline{\mathrm{S}}_{\mathrm{s}}-\mathrm{S}_{\mathrm{L}}^{\prime} \\
(\mathrm{cal} / \mathrm{mole} / \mathrm{deg})\end{array}$ \\
\hline 0.01053 & 11.4927 & 0.432 & -0.36542 & 0.215 \\
0.01228 & 10.6902 & 0.541 & -0.26680 & 2.503 \\
0.01404 & 10.1477 & 0.656 & -0.18310 & 3.972 \\
0.01491 & 10.0968 & 0.713 & -0.14691 & 3.980 \\
0.01579 & 10.0098 & 0.768 & -0.11464 & 4.129 \\
0.01667 & 10.0240 & 0.824 & -0.08407 & 3.941 \\
0.01754 & 10.0475 & 0.880 & -0.05552 & 3.730 \\
0.01842 & 10.4554 & 1.022 & +0.00945 & 2.041 \\
0.02018 & 10.5988 & 1.108 & 0.04454 & 1.390 \\
0.02105 & 10.7712 & 1.202 & 0.07990 & 0.640 \\
0.02193 & 10.8851 & 1.304 & 0.11528 & 0.089 \\
0.02281 & 10.9245 & 1.412 & 0.14983 & -0.203 \\
0.02368 & 10.9415 & 1.529 & 0.18441 & -0.420 \\
0.02456 & 10.9371 & 1.640 & 0.21484 & -0.544 \\
0.02544 & 10.8479 & 1.780 & 0.25042 & -0.402 \\
\hline
\end{tabular}


TABLE 10--Continued

\begin{tabular}{ccccc}
\hline $\begin{array}{c}\mathrm{V} / \mathrm{A} \\
\left(\mathrm{cm}^{3} / \mathrm{m}^{2}\right)\end{array}$ & $\begin{array}{c}\mathrm{q}_{\mathrm{st}} \\
(\mathrm{kcal} / \mathrm{mole})\end{array}$ & $\begin{array}{c}\mathrm{P} \\
(\mathrm{mm})\end{array}$ & $\log \mathrm{P}$ & $\begin{array}{c}\overline{\mathrm{S}}_{\mathrm{S}}-\mathrm{S}_{\mathrm{L}}^{\prime} \\
(\mathrm{cal} / \mathrm{mole} / \mathrm{deg})\end{array}$ \\
\hline 0.02632 & 10.7592 & 1.915 & 0.28217 & -0.245 \\
0.02719 & 10.6579 & 2.059 & 0.31366 & -0.043 \\
0.02807 & 10.5391 & 2.206 & 0.34361 & +0.226 \\
0.02895 & 10.4138 & 2.364 & 0.37365 & 0.516 \\
0.02982 & 10.2802 & 2.521 & 0.40157 & 0.844 \\
0.03070 & 10.1620 & 2.689 & 0.42959 & 1.119 \\
0.03158 & 10.0426 & 2.857 & 0.45591 & 1.406 \\
0.03400 & 9.6058 & 3.341 & 0.52388 & 2.586 \\
0.03600 & 9.3441 & 3.760 & 0.57519 & 3.245 \\
0.03800 & 9.1098 & 4.190 & 0.62221 & 3.830 \\
\hline
\end{tabular}


TABLE 11

Differential Entropy of Adsorption

High Pressure Data

\begin{tabular}{|c|c|c|c|c|}
\hline $\begin{array}{c}V / A \\
\left(\mathrm{~cm}^{3} / \mathrm{m}^{2}\right)\end{array}$ & $\begin{array}{c}\mathrm{q}_{\mathrm{st}} \\
(\mathrm{kcal} / \mathrm{mole})\end{array}$ & $\begin{array}{c}P \\
(\mathrm{~mm})\end{array}$ & $\log P$ & $\begin{array}{c}\bar{S}_{s}-S_{L}^{\prime} \\
(c a l / \mathrm{mole} / \mathrm{deg})\end{array}$ \\
\hline 0.07 & 7.9635 & 14.651 & 1.16587 & +5.254 \\
\hline 0.08 & 8.4846 & 17.240 & 1.23654 & 3.151 \\
\hline 0.09 & 9.0567 & 19.829 & 1.29730 & 0.921 \\
\hline 0.10 & 9.4180 & 22.418 & 1.35060 & -0.556 \\
\hline 0.11 & 9.7257 & 25.007 & 1.39806 & -1.824 \\
\hline 0.12 & 10.0306 & 27.596 & 1.44085 & -3.060 \\
\hline 0.13 & 10.2474 & 30.186 & 1.47980 & -3.979 \\
\hline 0.14 & 10.4088 & 32.774 & 1.51551 & -4.693 \\
\hline 0.15 & 10.5643 & 35.364 & 1.54855 & -5.375 \\
\hline 0.16 & 10.7275 & 37.953 & 1.57925 & -6.073 \\
\hline 0.17 & 10.8118 & 40.542 & 1.60790 & -6.491 \\
\hline 0.18 & 10.8599 & 43.131 & 1.63479 & -6.779 \\
\hline 0.19 & 10.8829 & 45.720 & 1.66011 & -6.973 \\
\hline 0.20 & 10.9273 & 48.309 & 1.68408 & -7.234 \\
\hline 0.21 & 10.9087 & 50.898 & 1.70670 & -7.274 \\
\hline
\end{tabular}


TABLE 11--Continued

\begin{tabular}{ccccc}
\hline $\begin{array}{c}\mathrm{V} / \mathrm{A} \\
\left(\mathrm{cm}^{3} / \mathrm{m}^{2}\right)\end{array}$ & $\begin{array}{c}\mathrm{q}_{\mathrm{st}} \\
(\mathrm{kcal} / \mathrm{mole})\end{array}$ & $\begin{array}{c}\mathrm{P} \\
(\mathrm{mm})\end{array}$ & $\log \mathrm{P}$ & $\begin{array}{c}\overline{\mathrm{S}}_{\mathrm{s}}-\mathrm{S}_{\mathrm{L}}^{\prime} \\
(\mathrm{cal} / \mathrm{mole} / \mathrm{deg})\end{array}$ \\
\hline 0.22 & 10.9119 & 53.486 & 1.72824 & -7.384 \\
0.23 & 10.8616 & 56.075 & 1.74877 & -7.306 \\
0.24 & 10.7669 & 58.664 & 1.76837 & -7.073 \\
0.25 & 10.6683 & 61.253 & 1.78713 & -6.822 \\
0.28 & 10.3382 & 69.020 & 1.83897 & -5.932 \\
0.31 & 10.0897 & 76.787 & 1.88529 & -5.296 \\
\hline
\end{tabular}




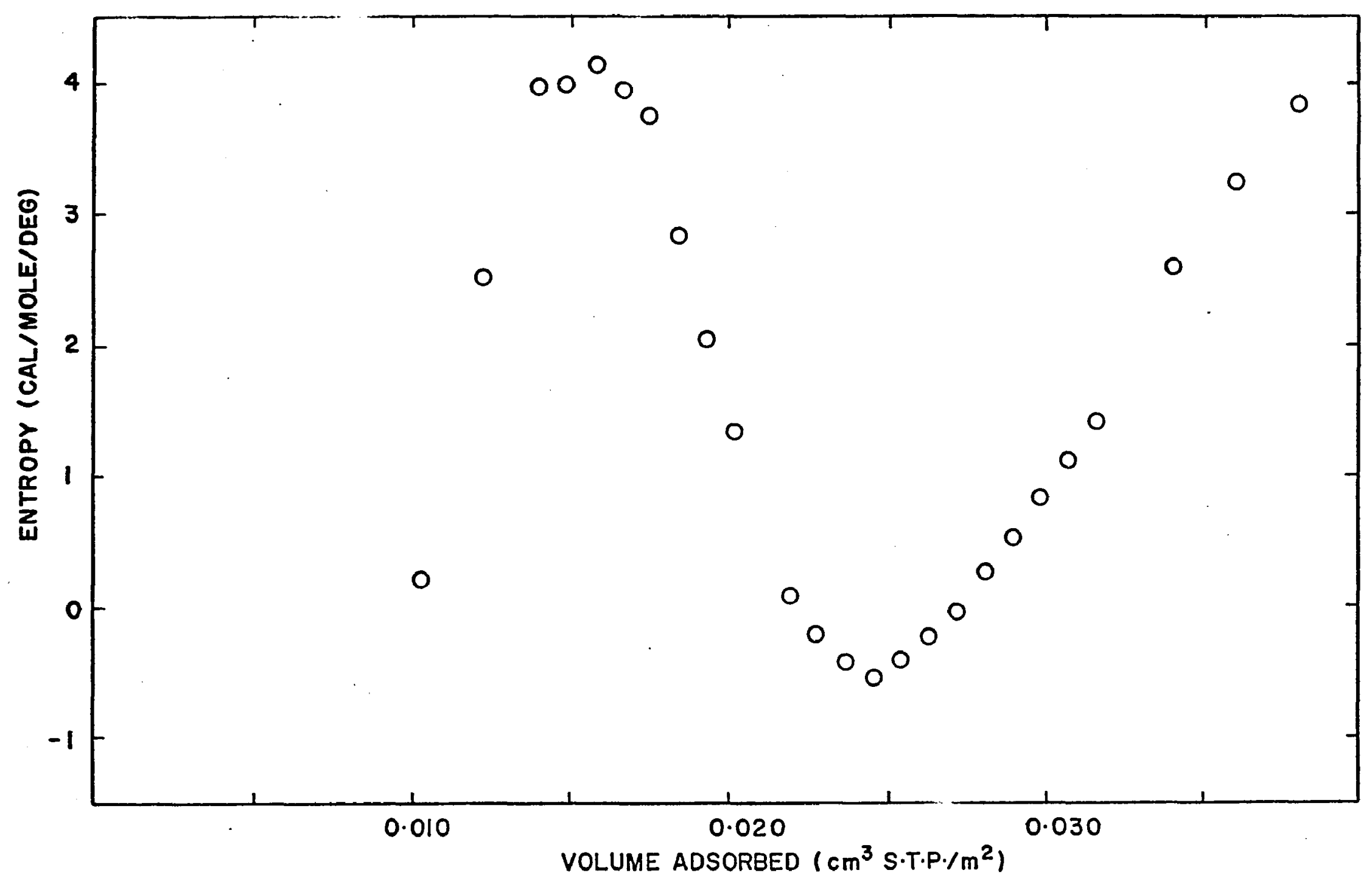

FIGURE 12. DIFFERENTIAL ENTROPY OF ADSORPTION, LOW PRESSURE DATA

$\stackrel{\infty}{\omega}$ 


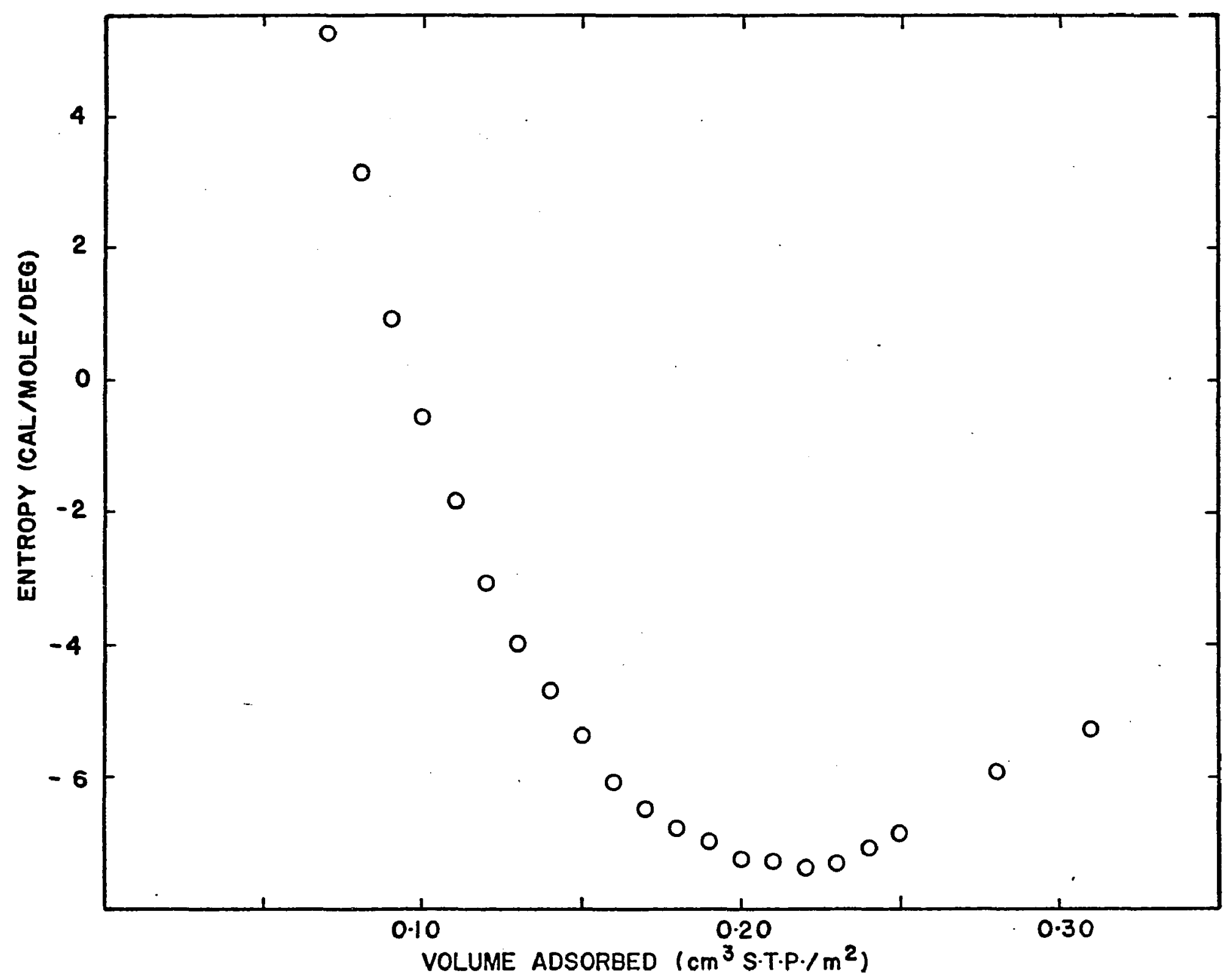

FIGURE 13. DIFFERENTIAL ENTROPY OF ADSORPTION, HIGH PRESSURE DATA 


\section{DISCUSSION}

\section{Adsorption of Water Vapor on Silver Iodide}

Examination of Figure 2 reveals that $\mathrm{Ag}(\mathrm{I})$ and $\mathrm{Ag}$ (II) differ markedly in their behavior toward water vapor. The amount of water vapor adsorbed by $\mathrm{AgI}$ (II), prepared by the reaction of iodine and silver in vacuo, increases almost linearly with increasing relative pressure. The isotherm is not typical of any of the five types of adsorption classified by Brunauer (1945). The adsorption isotherm for $\mathrm{AgI}(\mathrm{I})$, prepared by aqueous precipitation, is essentially type III which may be interpreted in terms of cooperative adsorption on a hydrophobic surface. A very large difference is apparent at relative pressures above 0.5 ; the amount of water vapor adsorbed per unit surface area is considerably greater for the silver iodide prepared by aqueous precipitation.

Since the silver iodide prepared by aqueous precipitation was known to contain a small amount of the salt formed from the counter ions of the silver and iodide-ions 
present during precipitation, $\mathrm{NH}_{4}^{+}$and $\mathrm{NO}_{3}^{-}$in this case, it is apparent that the surface properties of silver iodide are very sensitive to small amounts of impurities. It must be concluded that previously reported investigations of the surface properties of silver iodide prepared by aqueous precipitation are not, in general, typical of the uncontaminated silver iodide surface. The presence of varying amounts and kinds of coprecipitated impurities may we11 account for the stormy disagreement in the nature and extent of the surface properties of silver iodide reported by previous investigators.

It is not suggested that the silver iodide which was prepared by the direct reaction of silver and iodine is completely contaminant-free since such a state does not exist in reality but it is suggested that silver iodide free of the kinds and amounts of impurities which lead to anomolous reports in surface phenomena may be prepared by this method. Although the use of silver iodide as a cloud seeder is a subject which is outside the scope of this work, we must now consider previously proposed explanations for the ice nucleating properties of 
silver iodide to be of very doubtful validity for the uncontaminated silver iodide surface. Although previous investigators recognized the process of heterogeneous nucleation as a surface phenomenon, the possibility that contaminants might play a dominant role in determining the surface properties of silver iodide was not considered. This experiment was designed to detect any gross difference between the behavior of the two silver iodide preparations in the presence of water vapor. It is concluded that the major objective of the experiment has been fulfilled.

The Adsorption of Methanol Vapor on Silver Iodide Whenever the study of a solid surface is undertaken using the adsorption of a selected gas on the solid as a means of characterizing the surface itself, the investigator must be keenly aware of the limitations of the method. First, it is not yet possible to calculate the adsorption isotherms from so-called first principles alone. If the integral thermodynamic functions for the interaction of the gas with the solid surface are accurately determined, it is then possible to compare the experimentally 
determined functions with those calculated on the basis of a model of varying degrees of sophistication. As Steele (1963) points out in considering monolayer adsorption with lateral interaction on heterogeneous surfaces, the rigorous calculation of the adsorption properties of a solid of heterogeneous surface properties requires knowledge of the complete topography of the surface. He explains that functions giving the distribution of energy sites over the surface are highly sensitive to the nature of the imperfections that give rise to the heterogeneity of the surface.

In what might be termed the second best method of approach for the "theoretical" illucidation of the properties of heterogeneous surfaces, the investigator assumes that one of the simple isotherm equations is applicable over a small portion of the surface in consideration. This equation may be the Henry's law isotherm, the Langmuir isotherm or perhaps the two-dimensional analog of the van der Waals' equation. The constants in the selected equation are then said to be functions of surface coverage. Modern methods of computation permit the dependence of the 
various constants upon coverage to be analytically determined in a reasonable length of time. The function, which now takes the place of the constant in the original equation, is then interpreted as a theoretical distribution function. The validity of the approach is attributed to the ability to fit the experimental data to the model by means of the distribution function. This approach is harshly criticized by Adamson et al. (1966) in a recent treatment of physical adsorption on heterogeneous surfaces. By adjusting constants in three very different isotherm equations, Adamson calculates the adsorption of nitrogen on $\mathrm{BN}$ at $77.5^{\circ} \mathrm{K}$. The three calculated isotherms are essentially indistinguishable from the experimentally determined isotherm. Adamson states that the curve fitting approach is hopelessly insensitive to the choice of adsorption model and that a good fit to a model should be regarded with more suspicion than a poor fit given by a suitably chosen site distribution function.

A third approach is that taken in this work. Recognizing that a purely theoretical calculation of the surface properties of silver iodide is not yet within 
reach, and that curve fitting provides no new information, the attempt is made to make an accurate qualitative appraisal of the surface properties of silver iodide from the thermodynamics of its interaction with methanol vapor. One of the unavoidable hazards in this approach is clearly pointed out by Glossman (1963). In an extensive treatment of the thermodynamics of the interaction of argon with anatase $\left(\mathrm{TiO}_{2}\right)$, Glossman notes that there is no reliable method of rigorously separating the observed energy of interaction between the solid surface and the gas into the contribution due to adsorbate-adsorbate interaction and the contribution due to adsorbate-adsorbent interaction. Despite this difficulty, it is possible to qualitatively analyze the shapes of the differential heats and entropies of adsorption in terms of the nature of the adsorbent surface and the degree of 1ateral interaction between adsorbed molecules since these thermodynamic functions are particularly sensitive to changes in either. The presentation of a picture of the silver iodide surface which is consistent with the observed thermodynamic functions 
for the methanol-silver iodide system is therefore the objective of this investigation.

Examination of the low pressure adsorption isotherms shown in Figure 6 indicates concavity of the curves toward the pressure axis. The high pressure adsorption isotherms shown in Figure 8 are not typical of any of the five types of adsorption classified by Brunauer (1945). The absence of abrupt changes in slope in both low and high pressure isotherms and the concavity toward the pressure axis in the low pressure isotherms indicate that stacking effects are absent in the adsorbed phase. It thus appears that the choice of methanol for the adsorbate in characterizing the silver iodide surface was a good one since the complication of multilayer adsorption is absent in the adsorption isotherms.

The minimum in the low pressure heat of adsorption curve shown in Figure 10 occurs at approximately $0.016 \mathrm{~cm}^{3} / \mathrm{m}^{2}$ and presumably results from the interplay of two opposing effects. As the higher energy sites are filled on a heterogeneous surface, one would expect a decrease in the heat of adsorption. However, as more and 
more gas is adsorbed, one would expect an increase in the heat of adsorption as the adsorbed molecules begin to interact with one another. Thus the minimum results from the influence of these two effects. The minimum in the isosteric heat of adsorption at this point constitutes strong evidence for a heteroenergetic silver iodide surface. The differential entropy curve given in Figure 12 shows a maximum at essentially the same location suggesting a low degree of order for the adsorbed phase at this point.

The maximum in the low pressure heat curve occurring at approximately $0.024 \mathrm{~cm}^{3} / \mathrm{m}^{2}$ may again be interpreted in terms of the interplay of two opposing effects. Although the contribution due to lateral interactions is still tending to increase the heat of adsorption, the composite effect produced by the decreasing number of unoccupied higher energy sites and the decreasing number and intensity of the lateral interactions tends to decrease the heat of adsorption with increasing coverage. It thus appears that the higher energy sites are covered with a monolayer of methanol at this point. 
The higher pressure heat of adsorption curve given in Figure 11 shows a maximum in the isosteric heat at a coverage of approximately $0.20 \mathrm{~cm}^{3} / \mathrm{m}^{2}$. At this point genuine monolayer formation appears to have occurred. The maximum is easily explainable as resulting from the increasing heat of adsorption due to increasing lateral interaction opposed by the decreasing heat of adsorption as the adsorbed phase becomes more liquid-like in nature. Presumably the difference between the heat of adsorption and the heat of liquefaction would vanish as the number of adsorbed layers increased. The differential entropy of adsorption shown in Figure 13 shows a pronounced minimum at essentially the same coverage indicating a highly ordered adsorbed phase. The coverage of $0.20 \mathrm{~cm}^{3} / \mathrm{m}^{2}$ corresponds to an area per molecule of $18.6 \mathrm{~A}^{2}$ in the adsorbed phase. Evidently, monolayer formation has occurred at this point.

The maximum occurring in the low pressure heat curve corresponds to an area per molecule of $155 \mathrm{~A}^{2}$. Even standing alone this figure is highly unreasonable for the area occupied by a single methanol molecule in a 
monolayer but in view of the results in the preceding paragraph it is necessary to rule out monolayer formation at this low coverage. The only alternative is to accept the pseudo-monolayer proposal stated earlier. It is apparent that the higher energy sites which were detected with the low pressure heat curve must not be randomly distributed over the surface but rather must occur in patches or clumps on the surface.

It is concluded that the silver iodide surface has been fairly well characterized by this investigation. Interpretation of the thermodynamic data was relatively straightforward since three-dimensional clustering effects were shown to be absent in the adsorbed phase. It is now apparent that the silver iodide surface is highly heteroenergetic with about $12 \%$ of the surface consisting of the higher energy sites. It is also apparent that the higher energy sites are not randomly distributed over the surface but occur in patches on the surface. Although this investigation provides no information on the nature of the heterogeneities in the silver iodide surface, it is felt 
that a contribution has been made towards understanding the surface properties of silver iodide. 


\section{REF ERENCES}

Adamson, A. W., I. Ling, L. Dormant and M. Orem, J. Colloid Interface Sci., 21, 445 (1966).

Beattie, James A., Chem. Rev., 44, 141 (1949).

Birstein, S. J., J. Meteor., 12, 324 (1955).

Brunauer, S., P. H. Emmett and E. Teller, J. Am. Chem. Soc., $\underline{60}, 309$ (1938).

Brunauer, S., "The Adsorption of Gases and Vapors," Vo1. I, Princeton University Press, Princeton, N. J., 1945 .

Buff, F. P., J. Chem. Phys., 19, 1591 (1951).

Corrin, M. L. and N. S. Storm, J. Phys. Chem., 67, 1509 (1963).

Corrin, M. L., H. W. Edwards and J. A. Nelson, J. Atmos. Sci., 21, 565 (1964).

Coulter, L. V. and G. A. Candela, Z. Electrochem., 56, 449 (1952).

Everett, D. H., Proc. Chem. Soc., Lond., 38 (1957).

Frenke1, J., "Kinetic Theory of Liquids," Oxford University Press, Oxford, England, 1946.

Gibbs, J. W., "Collected Works," Longmans and Green and Co., New York, Vol. I, 1928.

Glossman, N., Ph. D. Dissertation, The University of Arizona, Tucson, 1963. 
Ha11, P. G. and F. C. Tompkins, Trans. Faraday Soc., 58, 1734 (1962).

Hi11, T. L., Advanc. Catalys., 4, 212 (1952).

Karasz, F. E., W. M. Champion and G. D. Halsey, Jr., J. Phys. Chem., 60, 376 (1956).

La Mer, V. K. and R. Gruen, Trans. Faraday Soc., 4ㅇ, 410 (1952).

La Mer, V. K., Ind. Eng. Chem., 44, 1270 (1952).

Lange, N. A., "Handbook of Chemistry," 10th ed., McGrawHil1 Book Co., Inc., New York, 1961, p. 1432.

Mason, B. J., "The Physics of Clouds," Oxford University Press, London, England, 1957.

Moskvitin, N. M., M. M. Dubinin and A. I. Sakharov, Izv. Akad. Nauk SSSR, Otde1. Khim. Nauk, 233(12), 2080 (1959).

Münde1, C. F., Z. phys. Chem., 85, 435 (1913).

Nelson, J. A., forthcoming publication.

Partington, J. R., "An Advanced Treatise on Physical

Chemistry," Vo1. I, Longmans, Green and Co., London, England, 1949, p. 561.

Reiss, H., Ind. Eng. Chem., 44, 1284 (1952).

Rosenberg, A. J., J. Am. Chem. Soc., 78, 2929 (1956).

Schaefer, V., Chem. Rev., 44, 291 (1949).

Steele, W. A., J. Phys. Chem., 67, 2016 (1963).

Tcheurekdjian, N., A. C. Zettlemoyer and J. J. Chessick, J. Phys. Chem., 68, 773 (1964). 
Thomson, W., Phil. Mag., (4) 42, 448 (1871).

Tompkins, L. M., D. A. Muus and T. Pearson, J. Geophys. Res., 68, 3537 (1963).

Volmer, M., Z. Electrochem., 35, 555 (1929).

Vonnegut, B., J. App1. Phys., 18, 593 (1947).

Wylie, R. G., Proc. Phys. Soc. (London), B66, 241 (1953).

Young, D. M. and A. D. Crowell, "Physical Adsorption of Gases," Butterworths, London, England, 1962, pp. 159-63.

Zettlemoyer, A. C., N. Tcheurekdjian and J. J. Chessick, Nature, 192, 653 (1961).

Zettlemoyer, A. C., N. Tcheurekdjian and C. L. Hosler, Z. angew. Math. Phys., 14, 496 (1963). 